\title{
Applying 3D-eco routing model to reduce environmental footprint of road transports in Addis Ababa City
}

\author{
Seifu Woldemichael Busho ${ }^{1^{*}}$ (D) and Daniel Alemayehu ${ }^{2}$
}

\begin{abstract}
Background: Climate change has emerged as a very important threat to economic development, atmosphere, and public health. One of the driving factors behind global climate change is road transportation. Therefore, the sector needs to take on the responsibility of addressing its negative impacts on the environment. This study seeks to find ways of mitigating the impacts of climate change. It pays particular attention to greenhouse gas emissions and other selected air pollutants based on a new navigation concept called eco-route, a 3D eco-routing transportation planning method that can help reduce the environmental footprints of Road transports in Addis Ababa city for distribution vehicles. The model applied in this study considered the road gradient, varying velocity or speed of vehicles, and weight of vehicles to evaluate gradient effects on consumption of fuel, $\mathrm{CO}_{2}$ and also other air pollutants emission. The model is applied in three scenarios within different vehicle weight ranges and three different cases in Addis Ababa.

Result: The finds of the study imply the eco-routes emission reduction potential from fuel and $\mathrm{CO}_{2}$ in the tested scenarios is up to $39.81 \%$ while other air pollutants account for $25.65 \%$. The results prove that eco routes have the ability of reducing Fuel consumption, $\mathrm{CO}_{2}$ and other air pollutant emission rate.

Conclusions: Eco routes have the potential to provide sustainable transportation opportunities for Addis Ababa city. This study recommends that eco-routes should be used instead of shortest and fastest routes where significant road gradients exist.
\end{abstract}

Keywords: Climate change, $\mathrm{CO}_{2}$ reduction, Eco route, Emission

\section{Background}

Road transportation systems are crucial elements of city infrastructure and showcase the economic growth of cities. Effective road transport planning and high user accessibility enable sustainable growth (Arora and Pandey 2011). However, it also brings congestion and emission of air pollutant (i.e. Particulate matter (PM), Volatile organic compounds (VOCs), Oxides of nitrogen $\left(\mathrm{NO}_{\mathrm{x}}\right)$ Carbon monoxide $(\mathrm{CO})$, and Carbon dioxide $\left(\mathrm{CO}_{2}\right)$, the greenhouse gases (GHG) that are primarily responsible

\footnotetext{
*Correspondence: seifamichael@gmail.com

1 Geomatics and Geoinformatics Engineering Chair, School of Civil Engineering and Architecture, Dire Dawa University, P.O. Box:1362, Dire Dawa, Ethiopia

Full list of author information is available at the end of the article
}

for global warming (Cervero and Golub 2007). According to the International Energy Agency, the Transportation industry is the main source of $\mathrm{CO}_{2}$ emissions (Baumert et al. 2005). Road transport is accountable for $75 \%$ of GHG emissions from the transportation sector (Madan 2012). Therefore, estimating and measuring vehicle emissions is a key task in air pollution management. It creates a good base to gauge the ecological impact assessment of road transport scenarios. Road transport emission estimation models are important in this regard. On the other hand, monitoring vehicle emissions in cities or study areas is important to calibrate emission models.

Road transportation is the most dominant transportation mode in Addis Ababa City. Roads in the city are constructed and maintained by the Addis Ababa City 
Road Authority (AACRA). Today, roads in the city have reached $3324 \mathrm{~km}$ in length and account for $12.21 \%$ coverage of the developed areas of the city. Following the population boom in the last quarter of the $20^{\text {th }}$ century, demand for transportation increased exponentially. The Addis Ababa City administration launched large transport projects to meet this demand and they are now in their expansion phases. However, these road network developments did not consider their environmental impact. In order to achieve environmental sustainability, the road sector must be held responsible for its role.

Substantial Carbon dioxide emission saving can be realized by optimizing routes for minimal fuel consumption (Toro et al. 2016). Geographic information system (GIS) was used to optimize fuel utilization and emission reduction for the purposes of this study. GIS is widely applicable in transportation network analysis (The Geography of Transport System 2006). Utilizing GIS functionalities, Emission Estimation Models which consider vehicle speed, road gradients, and the weight of vehicles as a fuel consumption factor can be used for optimization (LAT/EEA 2007; Scora et al. 2015).

An Eco-routing algorithm is a strong fuel consumption model that helps to identify low energy routes when vehicles travel from origin to destination and vice versa. Unlike the fastest and shortest routes, eco routes are always obtainable as vehicles reduce their fuel consumption consequently their emission level. To quantify the environmental footprints or impacts of eco routing strategies, fuel consumption and its corresponding emissions must be assessed or expected. (Minett et al. 2011).

Numerous authors have examined eco routing tactics (Coloma et al. 2017) used drivers' behavior in a small city to reduce emission. In this study for driver's performance evaluation vehicle speed, time, acceleration and deceleration and also vehicle number of stops were considered for the purpose of finding eco routing and driving effects on emission based on field-based traffic data. Also, in Jovičić et al. (2010) the purpose of this study was to estimate and reduce fuel and $\mathrm{CO}_{2}$ for communal vehicles. Moreover, the fuel-efficient routes are compared considering time and distance with the corresponding route. Andersen et al. (2013) used eco-weights on a study area road network based on can bus trajectories' fuel consumption and Global positioning system data to enable eco routes. Based on the generated data the authors compared eco-routes to the shortest and fastest routes. Moreover (Huang et al. 2018) takes the above authors' work further by using Autonomies to calculate fuel consumption in the study area road network. Eco-routes are compared with shortest and fastest routes again. The results showed that eco-routes were able to reduce fuel consumption.
In waste management case studies Tavares et al. (2009) proposed 3D route model for waste transportation aiming to minimize fuel consumptions. Li and Cheng-zhi (2014) applied an engineering system, for the collection of waste in cities with major urban central areas aiming to reduction of fuel consumption and emission from vehicles.

Routing models need to use spatial data such as geographic information systems (GIS). GIS is intelligent in data input, management and displaying geospatial information. As reported by Keenan (1998) and Schröder and Cabral (2019) proposed a model that uses GIS to provide a comparative result in routing applications.

As presented above, influencing factors such as time and distance are commonly used for the optimization of vehicles. Real-time traffic and speed of vehicles have also been considered within a specific range of the vehicle. However, vehicle engine productivity on emission and fuel consumption affected by road gradients, vehicle fuel consumption is higher on higher gradients and vice versa. Therefore, it would be valuable to address gradients and include a broad range vehicle weights in order to find more accurate fuel consumption in addition to increasing the percentage of eco routes' fuel-saving potential and emission estimation. Such a method is innovative and would deliver realistic fuel consumption and emission estimation.

In summation, this paper focuses on the role of eco routing which depends on the road gradients extracted from the digital elevation model of the study area in the city road network system. Furthermore, it uses an emission estimation model that considers different vehicle weight ranges and speeds. To enable fuel consumption and emission minimization this study uses GIS network analyst as a tool and other open-source data.

\section{Materials and methods Study area description}

Addis Ababa is fully urban. According to the Central Statistics Agency's (CSA) 2007 census results, 662,728 peoples were reported as living in 628,984 housing units, with an average of 4.2 persons per household. The city contains $22.9 \%$ of all urban residents in Ethiopia and contains $3.7 \%$ of the total population of the country. Addis Ababa's road network is highly affected by its topographic changes, resulting in positive uphill and negative downhills. With an average road gradient of almost $4 \%$, it can be expected that the road gradient has a substantial effect on fuel consumption and $\mathrm{CO}_{2}$ Emissions. Detailed location and map descriptions are shown in Table 1 and Fig. 1. 
Table 1 Location description

\begin{tabular}{ll}
\hline Addis Ababa City & \\
\hline Coordinates & $38^{\circ} 44^{\prime} 24^{\prime \prime} \mathrm{E} 9^{\circ} 1^{\prime} 48^{\prime \prime} \mathrm{N}$ \\
Climate & Subtropical highland climate \\
Area(total): & $519.482 \mathrm{~km}^{2}$ \\
Elevation & $2355 \mathrm{~m}$ \\
Time zone & Universal Time Coordinated (UTC+3) \\
\hline
\end{tabular}

\section{Road transportation in the city}

In the city of Addis Ababa, the dominant public transportation modes are automobiles and dry cargo. Standard city buses and mini-bus taxis are the most available and affordable means of public transportation for the majority of the residents. There are also private limited companies and governmental road freight transportations which give delivery to the customers within a city. As of 2019, a total of 596,084 types of vehicles were available (Addis Ababa City Transport Authority 2019). The proper movement of vehicles poses the greatest challenge for the city to establish a reliable and sustainable transportation system.

A project to improve the transport management systems by making heavy-duty distribution vehicles and public buses to traverse in selected lanes is in progress. The current research may prove instrumental in selecting an environmentally friendly road network for distribution vehicles, that takes into account the gradient and other environmental factors into consideration.

\section{Data and data acquisition}

The Data used in this study was obtained from different sources. The Road network data mainly digitized from Google earth image of 2019 on the study area at the spatial resolution of $10 \mathrm{~m}$, and ortho photos were used to georectify the digitized road networks. Advanced Land observing satellite (ALOS), Phased array L band synthetic aperture radar (PALSAR) of 12.5 spatial resolution was used as a digital elevation model for the study area obtained from Alaska satellite facility. GPS Coordinates of the origin-destination locations were collected using actual measurements in the field. Emission related to
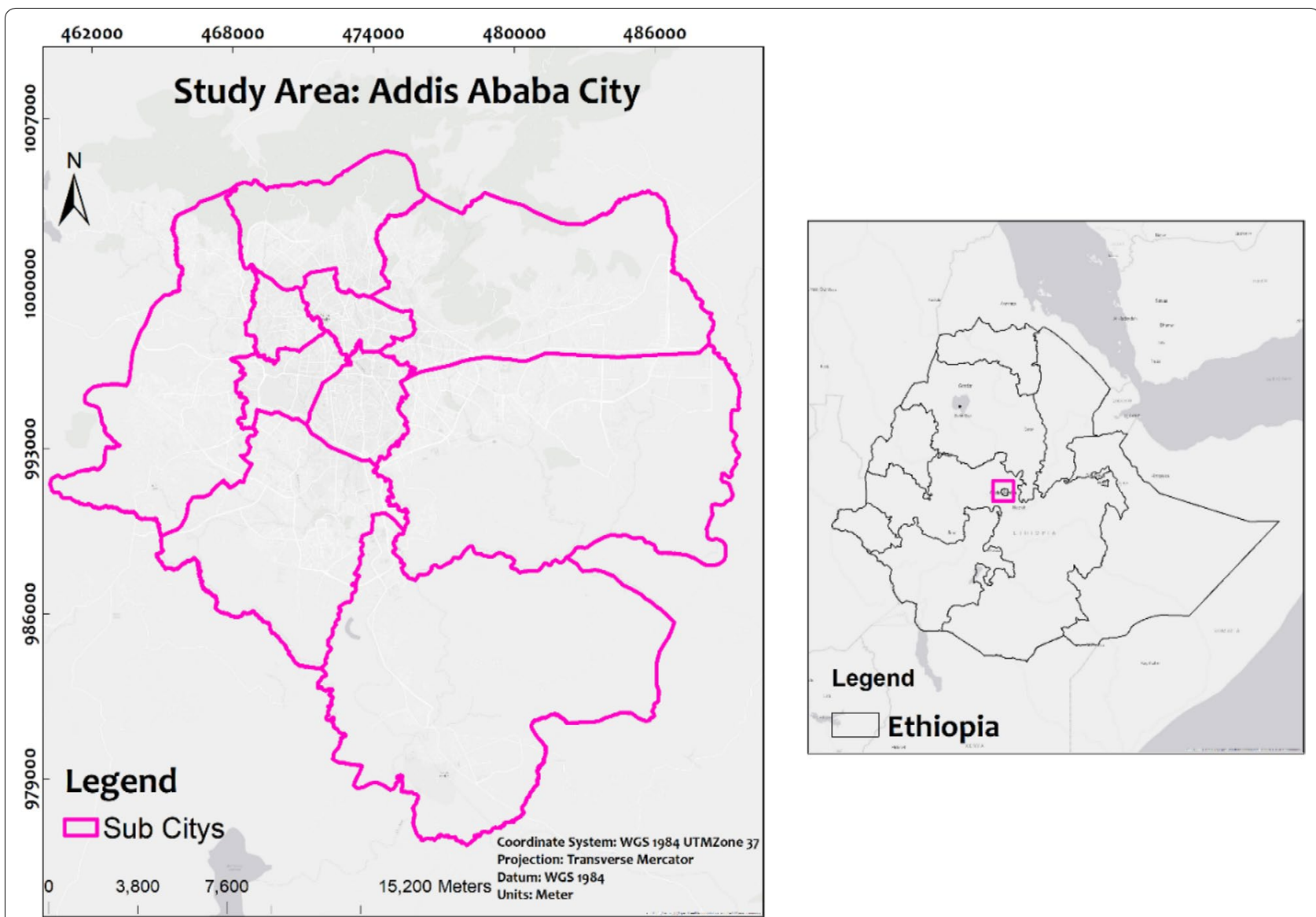

Fig. 1 Addis Ababa City map 
the data were obtained from Methodologies to Estimate Emissions from Transport (MEET) emission estimation model and other literatures.

\section{Methods}

This paper primarily espouses a methodology that finds optimal eco route networks that reduce the consumption of fuel and its related $\mathrm{CO}_{2}$. Additionally, other pollutant emissions for transporting cargo from origin to destination and vice versa are considered.

The model application was done in four steps: (1) Establishment of 3D-RN;(2) Fuel consumption and pollutant emission estimation by using Emission estimation Model; (3) Road network data set development and (4) Optimization for different scenarios and other attribute calculations by utilizing visual basic script options.

Figure 2 shows the general Work flow and procedures that were adopted in this study and form the basis for deriving the eco-route of the study area and subsequently the overall findings.

\section{Connecting 2D road Network with DEM: 3D road network generation}

At this stage, the 2D road segment consisting of 40,886 polyline records with functional class [motorway, principal arterial, sub arterial, collector and local streets] were pre-processed by adding speed attributes to fit study area speed limits based on the Addis Ababa City Road authority (AACRA)Standard: $\mathbf{8 0}$ for Motorway, $\mathbf{7 0}$ for Principal arterial, $\mathbf{6 0}$ for Sub-arterial and Collector, 30 for Local Street. The Street Hierarchy was also tabulated based on AACRA's Street Hierarchy functional classes standard: 1 for Motorway, 2 for Principal arterial, 3 for Sub arterial, $\mathbf{4}$ for collector, $\mathbf{5}$ for Local Streets. It also worked on 2D Road Network. Finally, ALOS PALSAR DEM [12.5 m resolution] was used to convert $2 \mathrm{D}$ road Networks to $3 \mathrm{D}$ Road Network. ArcMap was utilized to obtain gradients

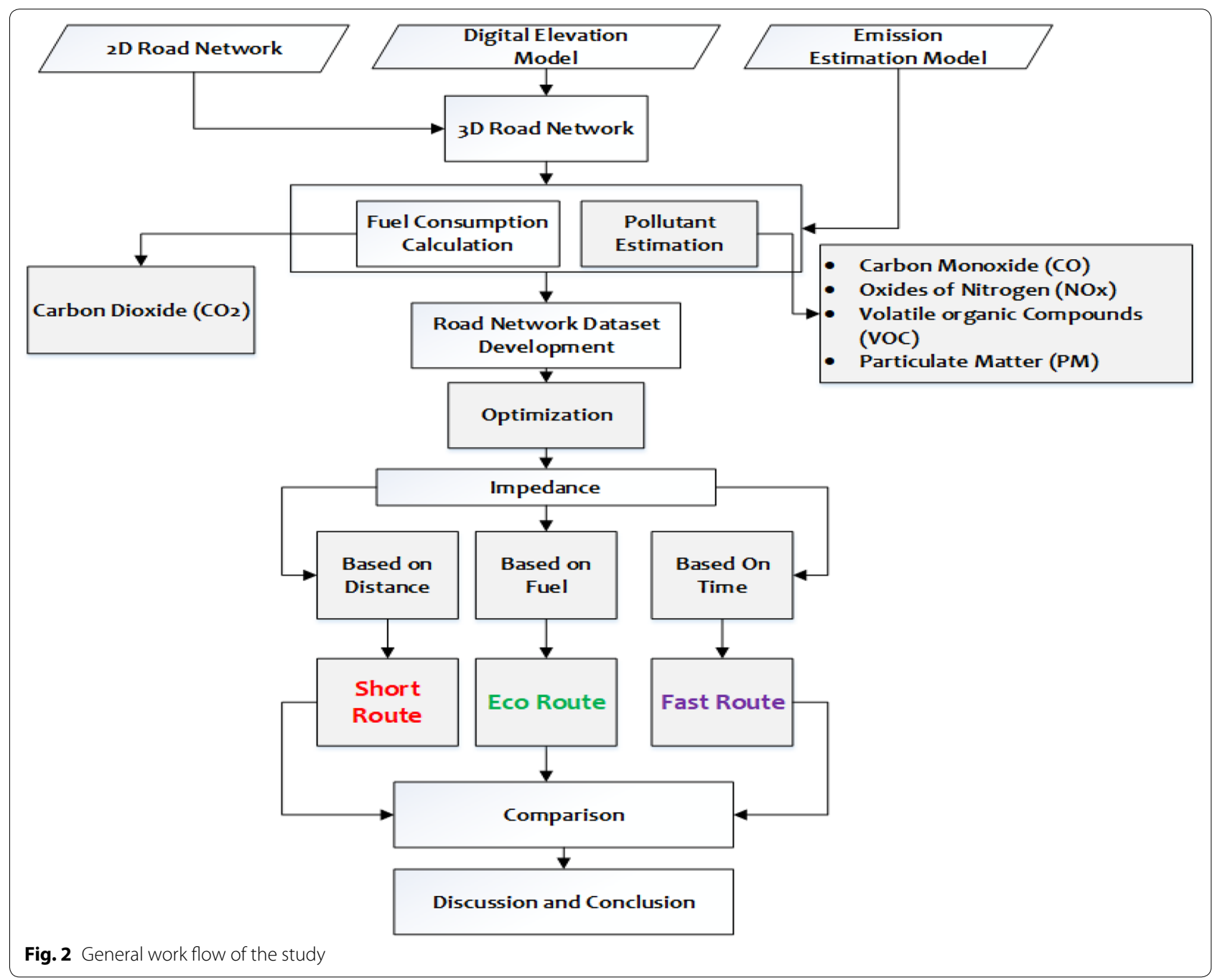


of a street network on the first step feature vertices to points on centerline feature class twice; one for beginning and one for end was generated.

Secondly, values are extracted from points on the start and end features classes. Finally, new field gradient were added by subtracting start elevation from end elevation values. Then values were divided by segment length and multiplied by hundred, which ultimately led to inaccuracies in gradient values. Therefore, to obtain more reliable slope it is necessary to determine with a higher resolution.

To obtain granular result, DEM was interpolated to the two-dimensional road networks to create three-dimensional road networks. Then, the created 3D road network was split at each turn, junction, and roundabout. Moreover, the straight road segments were split at every $10 \mathrm{~m}$ interval to create vertices at each 10 -m point. Therefore, more precise gradient values and three-dimension length of each edge were added as additional attributes in the road network data set. Finally, to determine the gradient direction from each value data was extracted using add surface information. Hence, the gradients' direction (+ve and -ve) was obtained based on edges start and end elevation. The results are tabulated as an additional attribute value in the network data set.

The 3D digital model and the road network for the city of Addis Ababa are shown in Fig. 3. The study area is faced with many undulating terrains, particularly on local streets due to DEM resolution on some parts of local street gradient values being unrealistic. To overcome these gradient values for the generated street segments within study boundaries higher than the permissible maximum restriction for road slopes, are reduced according to Bartlett (2015).

\section{Calculation of fuel consumption and pollutants emission estimation}

For this study, the method proposed in Methodologies to Estimate Emissions from Transport (MEET). MEET is based on road measurements and all its parameters are extracted from real-life experiments. It includes numerous vehicle technologies for different vehicle classes, such as weight classes $(<3.5,3.5-7.5,7.5-16,16-32$, and $>32$ tons) (Demiret al. 2014).

For calculations of emissions and fuel consumptions of a broad range of vehicles and engine types, MEET depends on a database of parameters. The emission factors and the parameters are gained by sampling a range of vehicles (i.e. heavy-duty vehicle range between 3.5 and 32 ton) (Kousoulidou et al. 2010). MEET formula methodology for estimating emissions is based on total fuel consumption data. Fuel consumptions and $\mathrm{CO}_{2}$ Rates estimations are speed dependent Regression functions introduced below for all vehicle classes. All calculations

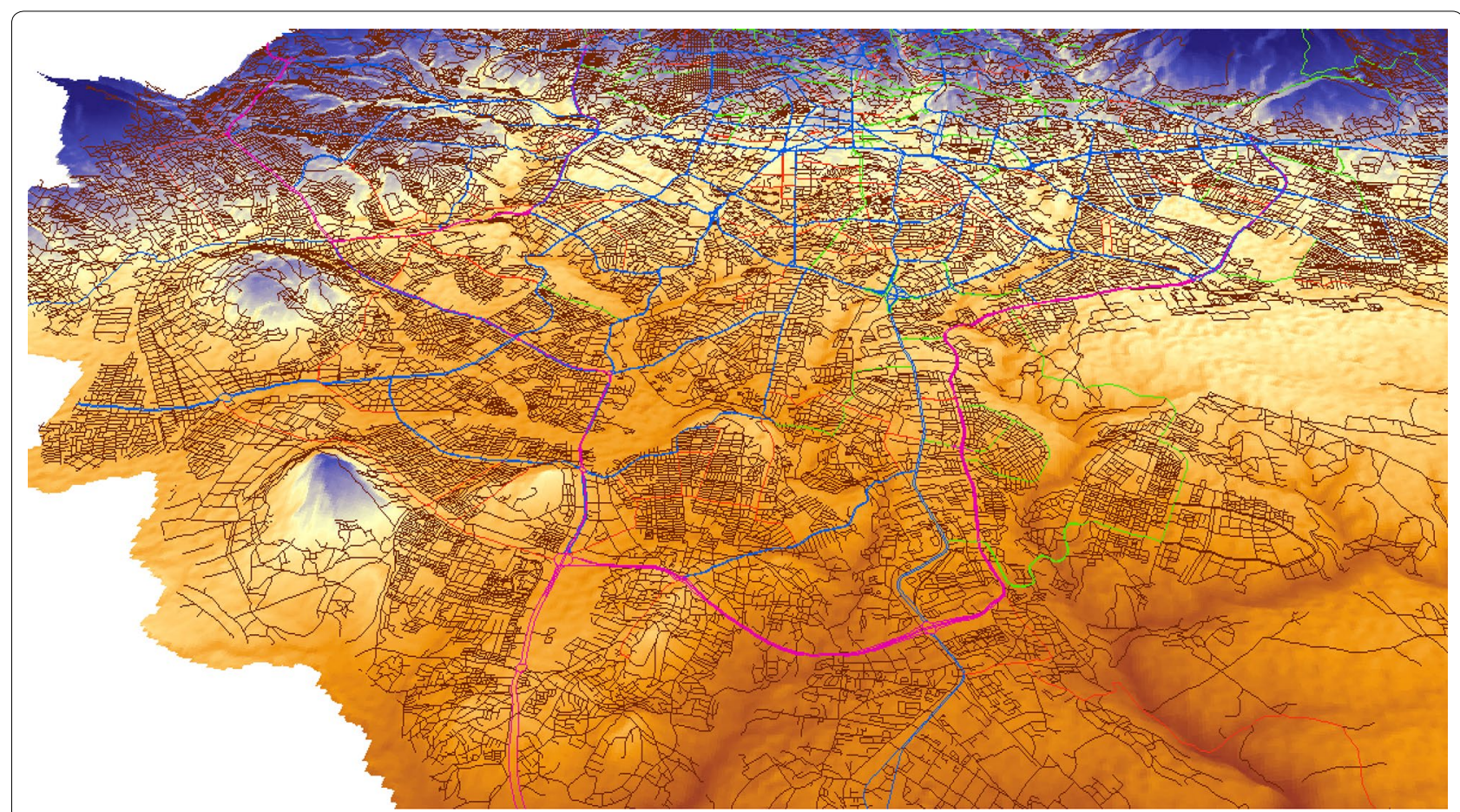

Fig. 3 A 3D digital model of Addis Ababa city showing its road network 
and estimations are done using the data available on MEET vehicle weight ranges (i.e. 3.5 up to 32 tones) for three scenarios and each scenario tested with three cases.

The basic fuel consumption and other pollutants expressed only in speed $(\mathrm{g} / \mathrm{km})$, and was obtained from MEET Model has been given below:

Scenario (1):

$$
\begin{aligned}
& \text { For V } 5-60 \quad 1425.2 \mathrm{~V}^{-0.7593} \\
& \text { For V } 60-100 \quad 0.082 \mathrm{~V}^{2}-0.0430 \mathrm{~V}+60.12
\end{aligned}
$$

Other Pollutants

$$
\begin{array}{llll}
\mathrm{CO} & \text { For V } & 5-100 & 37.280 \mathrm{~V}^{-0.6945} \\
\text { NOx } & \text { For V } & 5-50 & 50.305 \mathrm{~V}^{-0.7708}
\end{array}
$$

For V $50-100, \quad 0.0014 \mathrm{~V}^{2}-0.1737 \mathrm{~V}+7.5506$

$$
\text { VOC For V } \quad 5-100 \quad 40.120 \mathrm{~V}^{-0.8774}
$$

PM For V $\quad 5-100 \quad 4.5563 \mathrm{~V}^{-0.707}$

Scenario (2):

$$
\text { For } \mathrm{V} \quad 5-60 \quad 1068.4 \mathrm{~V}^{-0.4905}
$$

$$
\text { For } \mathrm{V} \quad 60-100 \quad 0.0126 \mathrm{~V}^{2}-0.6589 \mathrm{~V}+141.2
$$

Scenario (3):

$$
\begin{array}{lll}
\text { For } \mathrm{V} & 5-60 & 1595.1 \mathrm{~V}^{-0.4744} \\
\text { For } \mathrm{V} & 60-100 & 0.0382 \mathrm{~V}^{2}-5.163 \mathrm{~V}+399.3
\end{array}
$$

Based on the vehicle's category, corrections can also be applied to consider the gradient of street and load of vehicles' effects on the emissions.

\section{Gradient factor}

A road's uprising or down rising has the effect of ascending or descending the vehicle's fuel consumption and emission (EEA 1999). For street gradient class, the gradient correction factor calculated using the MEET model. The model provides a gradient correction factor for a range of ( -6 to $6 \%$ ) gradient. To include a broad range of gradient classes in a city road network, the given equations were adjusted to fit an exponential function. Equations (12-14) were also used as the road gradient correction factor for other pollutants They are expressed by the following equation, where RG represents the road gradient in percentage.

For scenario 1:
Table 2 Load factors applied to heavy duty vehicles

\begin{tabular}{ll}
\hline Pollutant & Load factor (Ip) \\
\hline CO & 0.21 \\
NOx & 0.18 \\
VOC & 0 \\
PM & 0.08
\end{tabular}

Table 3 Load correction factors applied to heavy duty vehicles

Load correction factor (Lcf)

\begin{tabular}{lll}
\hline Pollutant & Empty load & Complete load \\
\hline CO & 0.79 & 1.21 \\
NOx & 0.82 & 1.18 \\
VOC & 1 & 1 \\
PM & 0.92 & 1.08 \\
\hline
\end{tabular}

$$
\mathrm{G}_{\mathrm{CF}}=0.213 \mathrm{e}^{0.165 \mathrm{RG}}
$$

For scenario 2:

$$
\mathrm{G}_{\mathrm{CF}}=0.419 \mathrm{e}^{0.180 \mathrm{RG}}
$$

For scenario 3:

$$
\mathrm{G}_{\mathrm{CF}}=1.0458 \mathrm{e}^{0.187 \mathrm{RG}}
$$

\section{Vehicle load factor}

The higher the vehicle weight the higher its fuel consumption and emission and also the same for vice versa (Tavares et al. 2009).

$50 \%$ of the load for emission factor is corrected to tolerate different load conditions with the use of the following Eq. (15).

$$
\mathrm{L}_{\mathrm{cf}}=\left[1+2 \mathrm{cf} \frac{(l p-50)}{100}\right]
$$

where, $\mathrm{L}_{\mathrm{cf}}=$ emission factor corrected of the fuel consumption in $[\mathrm{g} / \mathrm{km}] ; \mathrm{lp}=0$ for empty load vehicle and $\mathrm{lp}=100$ for fully load; $\mathrm{cf}=$ load correction factor of the FC which is 0.18; For Loaded vehicles Lcf of 1.18 and for Unloaded Vehicles Lcf of 0.82 was applied.

The equation above (15) was also used to consider vehicle load for other pollutant emission estimation calculations. The actual load factor for pollutants is given in MEET and applied for this study. The load factors applied for pollutants is given in Table 2 while Table 3 shows the load correction. 
MEET Suggests the total fuel consumption in gram as in Eq. (16) and for all pollutants, (i.e. CO, NOx, VOC, PM) the total Emission per Road length is calculated in gram as in Eq. (17).

$$
\mathrm{FC}=\mathrm{FcV} * \mathrm{G}_{\mathrm{CF}} * \mathrm{~L}_{\mathrm{cf}} * \mathrm{D}
$$

Total Emission of Pollutant $=\mathrm{Pv} * \mathrm{GCF} * \operatorname{Lcf} * \mathrm{D}$

where: $\mathrm{FcV}=$ Speed factor for $\mathrm{Fc}, \mathrm{P}_{\mathrm{V}}=$ Pollutants speed factor, $G_{C F}=$ Gradient Correction Factor, $\mathrm{L}_{\mathrm{cf}}=$ Load Correction Factor, $\mathrm{D}=$ Distance in $\mathrm{km}$.

For real application, fuels in grams have been converted to Liter [L].

Diesel for automotive use is around $832 \mathrm{~g} / \mathrm{L}$.

Therefore:

$$
\mathrm{Fc}_{\text {Liter }}=\frac{F C[\mathrm{~g}]}{832\left[\frac{\mathrm{g}}{\mathrm{L}}\right]}
$$

The calculated fuel consumption values are used as an impedance to find eco routes in a network. For comparison, the road networks are completed with time attribute, length and allowed road functional class velocity expressed in Eq. (19).

$$
\mathrm{T}[\mathrm{h}]=\frac{3 D \text { distance }[\mathrm{km}]}{\text { Velocity }\left[\frac{\mathrm{km}}{\mathrm{h}}\right]} \text { used for fast routes }
$$

$\mathrm{L}[\mathrm{km}]=3 \mathrm{D}$ distance used for short routes.

Moreover, $\mathrm{CO}_{2}$ emissions rates are estimated based on fuel consumption only for each scenario. The following Eq. (20) is applied from the MEET methodology.

$$
\begin{aligned}
& \text { Weight of } \mathrm{CO}_{2} \\
& \quad=44.011(\text { wight of fuel } /(12.011+1.008 * \mathrm{rH} / \mathrm{C}))
\end{aligned}
$$

where: $\mathrm{rH} / \mathrm{C}=$ hydrogen to carbon ratio in the fuel $(\sim 2.0$ for diesel).

\section{Road network data set development}

Transport networks are mostly done in a GIS environment by the Network dataset. Network datasets are made of network elements. Network elements are created from point or line features to create the network dataset. Network elements contain attributes that change navigation over the developed network. Network attributes help to regulate traversing ability over the network. In this study, a one-way restriction was applied while solving the analysis. The hierarchy was given according to the road functional class: how drivers generally select the level of a street to travel. It is predictable that drivers choose high order roads rather than low order roads. For this study, vertex connectivity was selected. And finally, Elevation fields were considered to help improve the connectivity at line ends. They contain elevation information that consider vehicles passing overpasses, underpasses and normal streets in the network effectively.

\section{Optimization}

The route optimization was done with ArcMap Network Analyst. In this study, the route optimization primarily focuses on minimizing fuel usage to find eco-routes in a network that connects origin-destination points. Additionally, time and distance attributes are added to be used as cost attributes of the network. This study mainly aims to reduce vehicle environmental footprints. Therefore, reduction in fuel is not questionable.

For each step, terrain and fuel consumption module was developed. The modules share information stored in a spatial database created in the GIS environment. Figure 4 shows the structure of the developed model with its spatial data base and modules.

In this study, three scenarios which incorporate the different vehicle weight classes available in Addis Ababa were introduced to test different routing conditions.

Most fuel consumption models concentrate on vehicle, traffic, and environmental influences but do not capture driver related issues which are relatively difficult to measure (Demir et al. 2014). However, this study focuses on environment related influences (i.e. Roadway gradient effects on fuel consumption).

For this study design, the sample vehicle categories with a significant influence on road transportation emissions were selected based on vehicle weight classes. Samples of vehicles were selected from distribution vehicle private limited companies. The companies' vehicles, including distribution vehicles, were selected, based on their weight (i.e. 3.5-32 tons), engine type (i.e. diesel), and production year (i.e. 2010 models). Their total number of vehicles was also selected: Company 1-15 vehicles, Company 2-13 vehicles and Company 3-8 vehicles. Then, the vehicle weight classes were grouped into three scenarios. The first Scenario for diesel HDV is from 3.5 to 7.5 tons. The second scenario for diesel HDV is from 7.5 to 16 tons and the third scenario for diesel HDV from 16-32 tons. All scenarios are implemented in the GIS network analyst environment. Each scenario contains three cases with different loading and routing conditions. The overall implementations are tabulated in Table 4. 


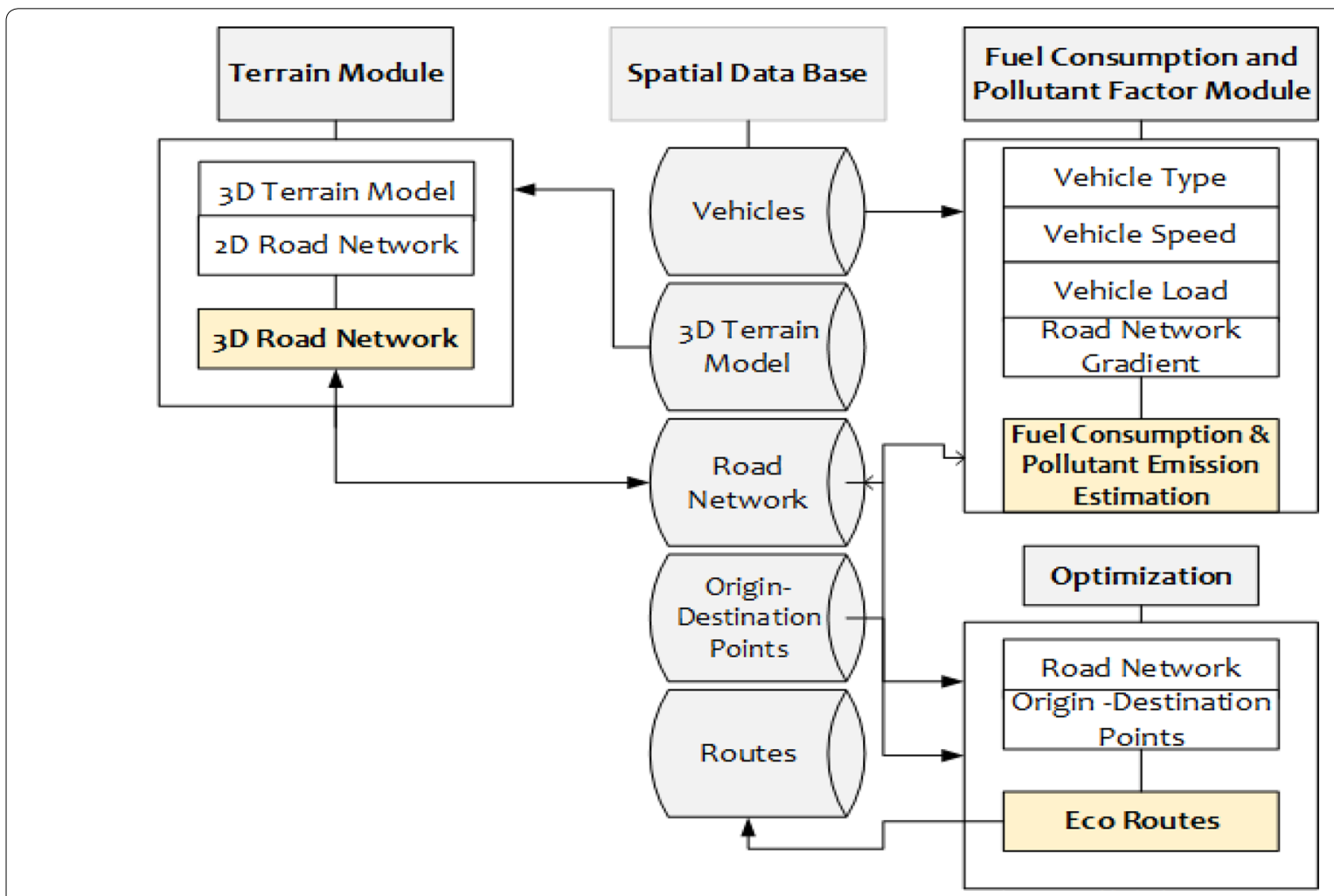

Fig. 4 Structure of the developed model showing spatial data base and its modules

Table 4 Scenario implementation for the methodology

\begin{tabular}{|c|c|c|c|c|c|}
\hline Scenarios & Cases & Weight class [ton] & Loading condition & Routing & Network analyst solver \\
\hline \multirow[t]{3}{*}{1} & 1 & $3.5-7.5$ & Loaded & Simple & New route \\
\hline & 2 & & & Full distribution & Closest facility solver \\
\hline & 3 & & Unloaded & Back Haul & \\
\hline \multirow[t]{3}{*}{2} & 1 & $7.5-16$ & Loaded & Simple & New route \\
\hline & 2 & & & Full distribution & Closest facility solver \\
\hline & 3 & & Unloaded & Back haul & \\
\hline \multirow[t]{3}{*}{3} & 1 & $16-32$ & Loaded & Simple & New route \\
\hline & 2 & & & Full distribution & Closest Facility Solver \\
\hline & 3 & & Unloaded & Back haul & \\
\hline
\end{tabular}

\section{Results}

At this stage, the route results are compared with different criteria, including travel time, fuel consumption and distance. Additionally, $\mathrm{CO}_{2}$ Emission estimation for all scenarios and air pollutant emissions for scenario 1 were estimated for routes. The cost of fuel was also estimated.

\section{Scenario 1}

This scenario simulates a bottled water market distribution process utilized by a supplier for Aqua Addis Bottled
Water. The company uses 15 trucks to supply 49 Supermarkets and return empty load to the factories. Supermarkets are a randomly assigned. Thus, each truck can supply 15 supermarkets in different locations and return to deliver to other destinations.

\section{Case 1}

Using scenario 1, in case 1 fuel and emission levels for heavy duty vehicle (HDV > 3.5 tons) with full loads were tested from the origin point to a single supermarket 
(correction factor for load 1.18). Routes are separately generated for fuel consumption, time and distance. The resulting three routes are displayed in Fig. 5.

As shown in Fig. 5, the shortest and fastest routes which mainly utilize Principal Arterial and Sub arterial streets for long distances overlap because the routes are not optimized for fuel consumption. In contrast, an ecoroute optimized for fuel consumption prefers lower gradients which yield fuel and $\mathrm{CO}_{2}$ emission saving with a potential of up to $39.81 \%$ more than its alternatives.

\section{Case 2}

Under scenario 1, Case 2 tests the fuel and emission levels by heavy duty vehicles (HDV $>3.5$ tons) from origin to each supermarket with complete loads (correction factor for load 1.18). Routes are separately generated for fuel consumption, Time and Distance. The resulting one hundred forty-seven routes are displayed in Fig. 6.

Eco routes optimized for fuel consumption prefer lower gradients which yield fuel and $\mathrm{CO}_{2}$ emission saving potential of up to $35.43 \%$ more than its' alternatives, whereas the total travelled distance is longer for each set of routes. However, the fastest route is faster than the eco-routes.

\section{Case 3}

Case 3 under scenario 1 tests the fuel and emission levels for destination market to origin. However, for the backhaul (CF Load of 0.82) is implemented to account for empty returning trucks. To consider returning trucks from the market routes are here again separately generated for fuel consumption, Time and Distance. The resulting one hundred forty-seven routes are displayed in Fig. 7.

In this case 3 scenario 1 also the eco-routes yields fuel and $\mathrm{CO}_{2}$ emission savings of about $27.08 \%$ compared to its alternatives, again the total travelled distance is longer for each set of routes. However, the fastest route is faster than the eco friendliest route.

\section{Scenario 2}

This scenario simulates Moha Soft Drinks' scheduled and demand-based product distribution from their summit plant to the market. There are 13 trucks that supply 50 hotels and bar market places and return empty bottles to

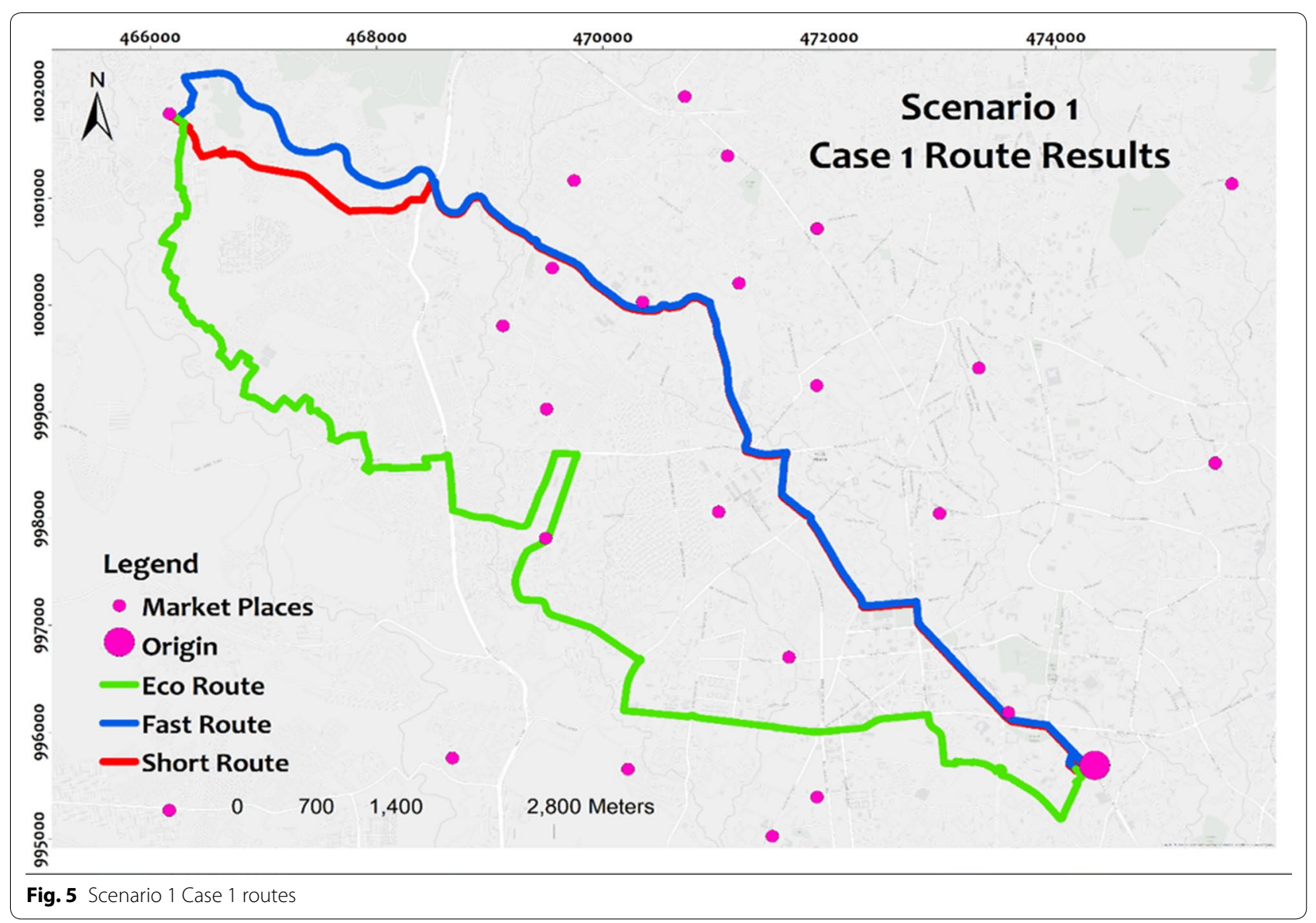




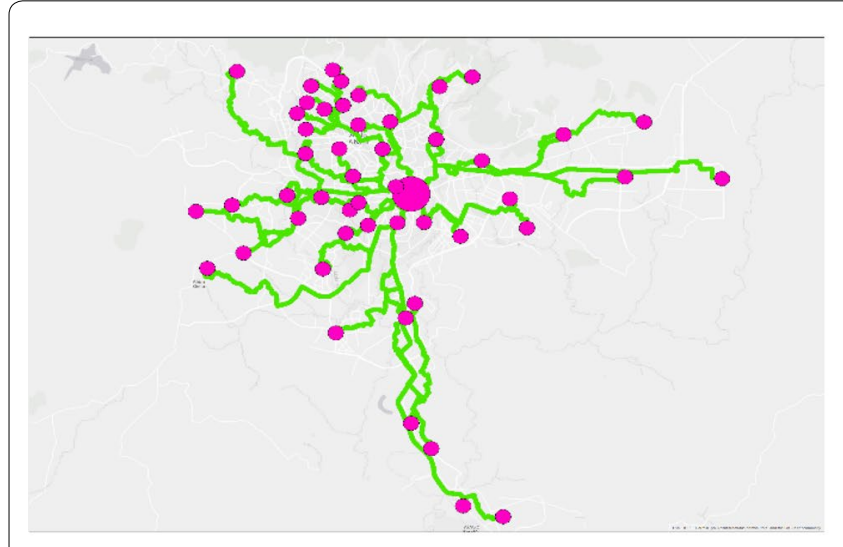

\section{Scenario 1 Case 2 Route Results}

\section{Legend}
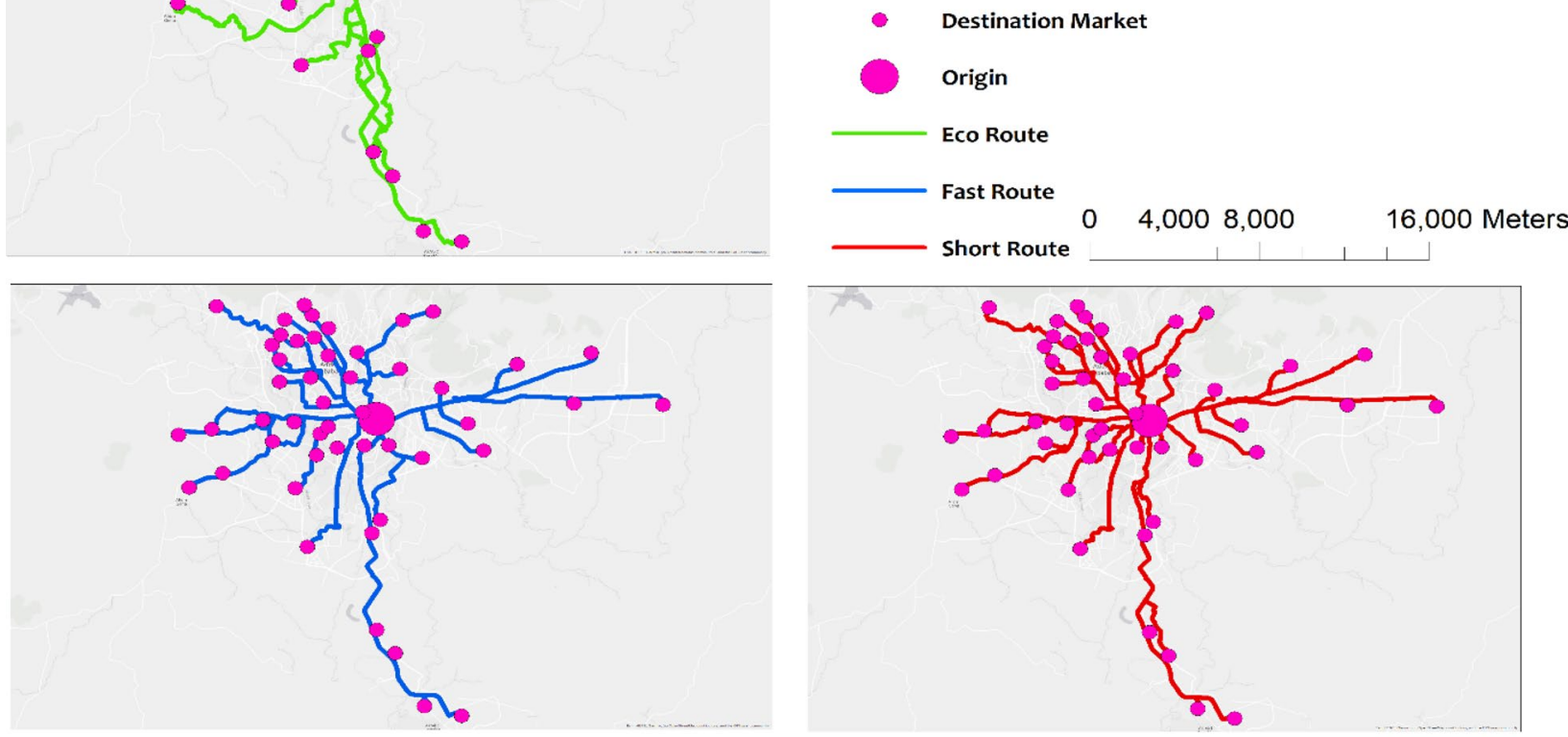

Fig. 6 Scenario 1 Case 2 routes

the origin point. Each market place is assigned according to the company's schedule. Therefore, each truck can supply 13 hotels and bars in one journey and return to make deliveries to the remaining destinations in one day.

\section{Case 1}

In scenario 2 of case 1 , the same principles as that of scenario 1 case were applied. This case under scenario 2 works for origin to a single supermarket. Routes are separately generated for fuel consumption, time and distance. The resulting three routes are displayed in Fig. 8.

The shortest and fastest routes overlap each other at the beginning and end, as they mainly utilize Principal Arterial and Sub arterial streets, with the Summit-Salhite-Mihret road as the preferred initial. However, ecoroutes at those locations prefer lower gradients as shown in Fig. 8, which yields fuel and $\mathrm{CO}_{2}$ emission saving potential of about $13.91 \%$ from its alternatives.

\section{Case 2}

Under scenario 2 Case 2 a completely loaded supply of soft drinks is sent to each market location. One market place is supplied by a single truck. Routes are separately generated for fuel consumption, time and distance. The resulting total of 150 routes is displayed in Fig. 9.

Eco routes optimized for fuel consumption again prefer lower gradients which yield fuel and $\mathrm{CO}_{2}$ emission saving potential of about $13.20 \%$ from its alternatives, whereas the travel distance is longer. However, the fastest route is faster than the eco routes.

\section{Case Study 3}

Case 3 under scenario 2 simulated backhauls from destination market to origin to study returning trucks from the market. Routes are separately generated for fuel consumption, time and distance. The resulting total of 150 routes is displayed in Fig. 10.

Here in scenario 2 case 3 again eco routes optimized for fuel consumption prefer lower gradients which yield fuel and $\mathrm{CO}_{2}$ emission saving potential of about $9.81 \%$ from its alternatives, whereas the travel distance is longer. However, the fastest route is faster than the eco routes.

\section{Scenario 3}

This scenario simulates the supply of a vehicle Gas (i.e., Diesel and gasoline) to a service station utilized by Oilibiya private limited company. Fuel is distributed from a 


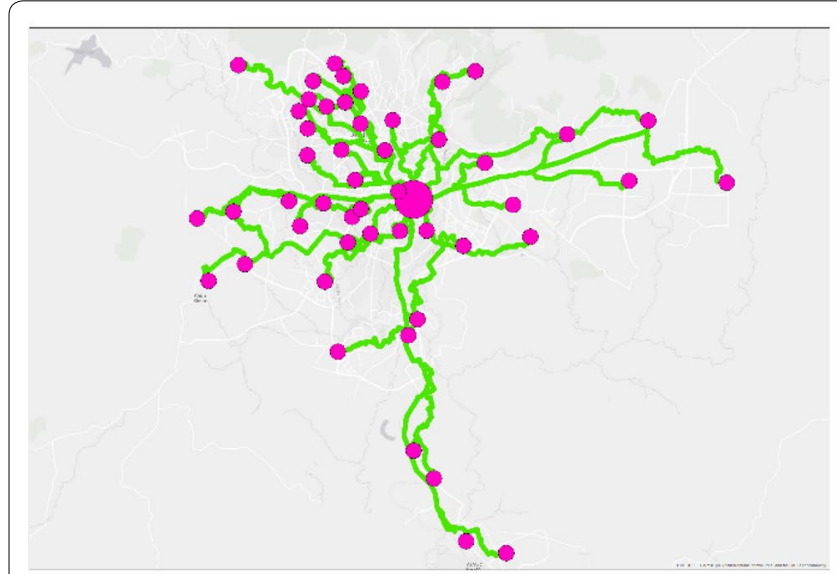

\section{Scenario 1 Case 3 Route Results}

\section{Legend}
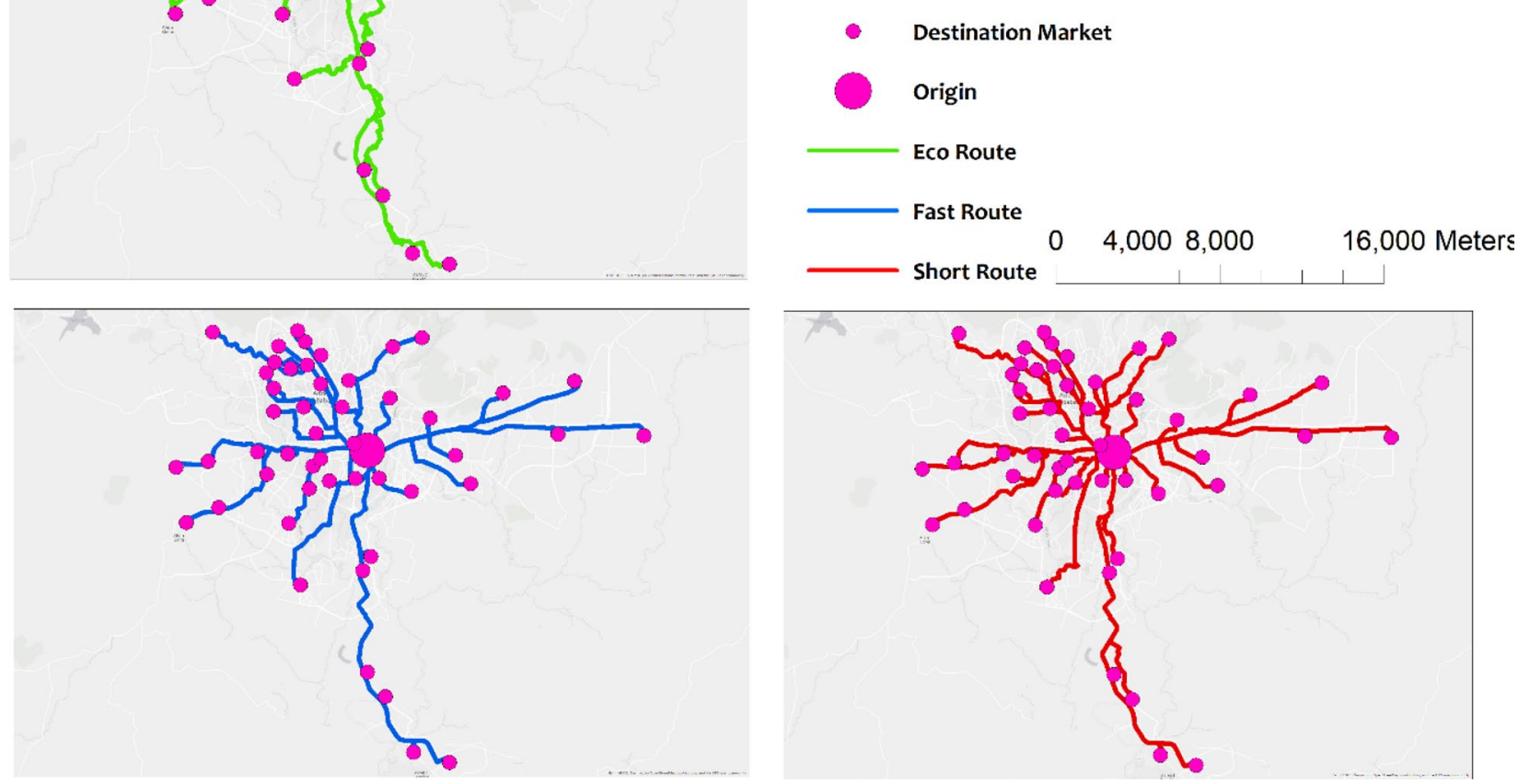

Fig. 7 Scenario 1 Case 3 routes

depot in Gotera to service stations on a demand-based schedule. Therefore, $8 \mathrm{HDV}$ trucks are available in the company to supply 27 service station and return to the depot. Each truck can supply 8 service stations once and return back and make deliveries for the remaining fuel stations. The vehicle range incorporated in this scenario is HDV $16-32$ tons.

\section{Case 1}

Under scenario 3, the principles applied in scenarios 1 and 2 of case 1 are applied to Case 1 again. As such, routes are separately generated for fuel consumption, time and distance. The resulting three routes are displayed in Fig. 11.

The fastest route tends to jump on motorways (ring road) and the shortest routes mainly utilize principal arterial streets which are not optimized for fuel consumption (FC). However, eco routes initially utilize the Gotera overpasses and then tend to use sub arterial streets and local streets as shown in Fig. 11. All three routes partially overlap at initial and destination kilometers. But, eco routes prefer the lower gradients of a street network which can yield Fuel and $\mathrm{CO}_{2}$ emission saving of up to $19.48 \%$ from its alternatives.

\section{Case 2}

Case 2 under scenario 3 simulated the supply of Fuel to each Service station locations (i.e. the depot to 27 service stations) with a completely loaded vehicle. Each service station is supplied by a single truck. The routes are generated for fuel consumption, time and distance. The resulting total of 81 routes is displayed in Fig. 12.

Figure 12 results shows that once again eco routes optimized for fuel consumption prefer lower gradients which yield fuel and $\mathrm{CO}_{2}$ emission saving potential of about $19.32 \%$ from its alternatives, whereas the travel distance is longer. However, the fastest route is faster than the eco routes.

\section{Case study 3}

This scenario was applied to case 3 for the backhaul to account for empty returning trucks. The routes are generated for fuel consumption, time and distance. The resulting total of 81 routes is displayed in Fig. 13. 


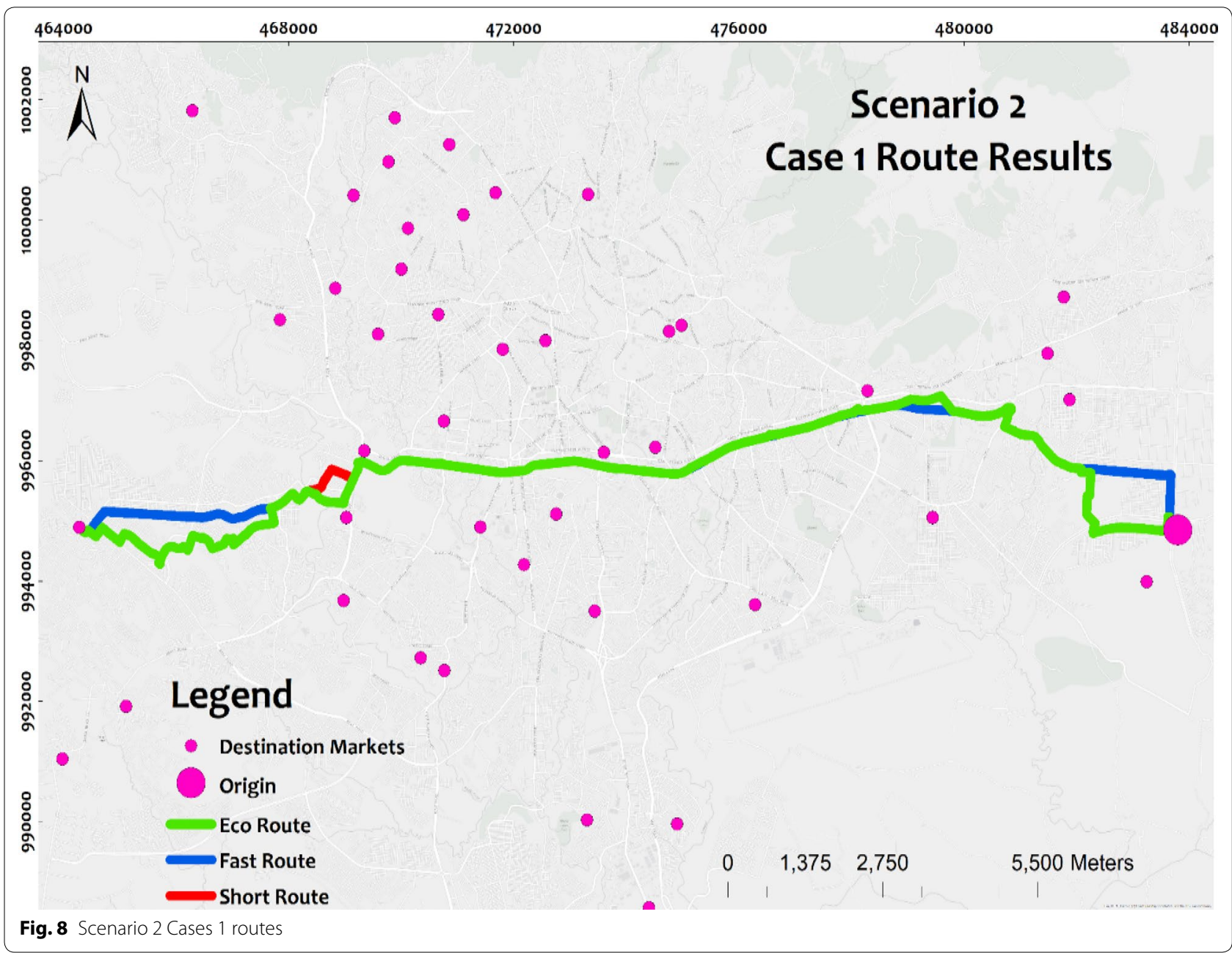

In scenario 3 case 3 eco routes optimized for fuel consumption again prefer lower gradients which yields fuel and $\mathrm{CO}_{2}$ emission saving potential of about $19.32 \%$ from its alternatives, whereas the travel distance is longer. However, the fastest route is faster than the eco routes.

\section{Parameter comparison results for three scenarios}

The comparative results in Tables 5 and 6 show that the eco routes' ability in reducing fuel consumption and $\mathrm{CO}_{2}$ emission is up to $39.81 \%$. Furthermore, in the tested scenarios, Eco routes fuel and emission saving are high in scenario one, moderate in scenario 2 and lowest in scenario 3 .

\section{Other pollutants result for scenario 1}

In many urban areas, road transportation was the main source of air pollution. For this study Emissions of pollutants from generated routes focused on Carbon
Monoxide (CO), Particulate Matters (PM), Oxides of Nitrogen (NOx) and, Volatile Organic Compounds (VOC). Like fuel consumption and $\mathrm{CO}_{2}$ emission, at this stage different pollutants obtained from the shortest and fastest routes were compared with eco routes. The results are presented below.

\section{Scenario 1 pollutant result}

In this scenario, the results are accumulated from the scenario (1) which is generated for fuel consumption and $\mathrm{CO}_{2}$ emissions. Emission rate results are presented below for each case.

The three route results shown in Fig. 14 show an overwhelmingly similar trend. In scenario 1 case 1 Pollutant Emission Results PM has the lowest emissions. The shortest routes cause the total high emission of $\mathrm{CO}$. But eco routes show significant emission saving potential of CO. Moreover, those eco routes have significant emission 


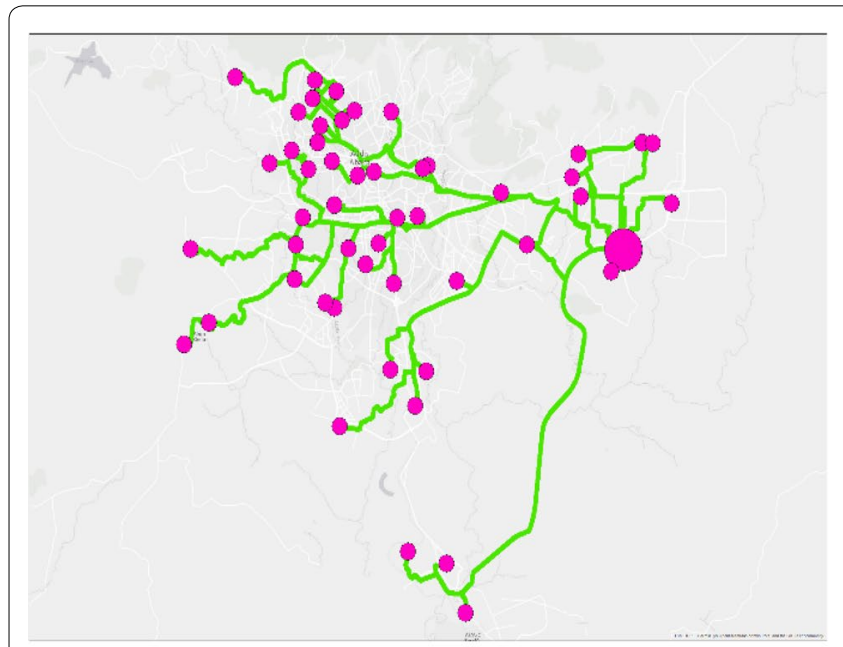

\section{Scenario 2}

\section{Case 2 Route Results}

\section{Legend}

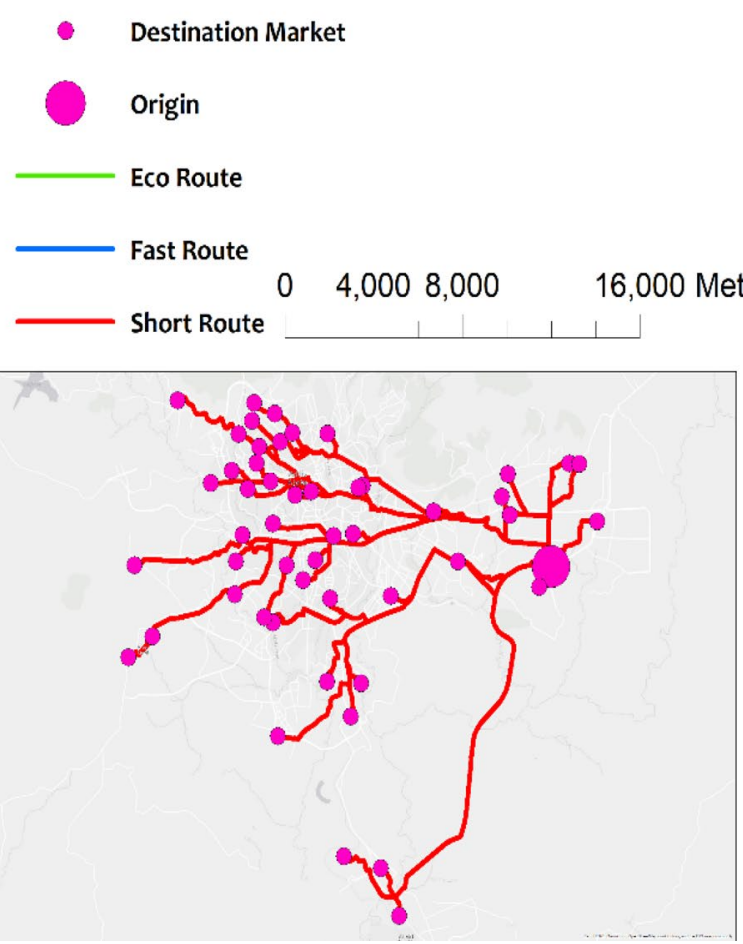

Fig. 9 Scenario 2 Case 2 routes

saving potential with respect to their alternatives in all pollutants (Table 7).

The three routes in Fig. 15 follow the same trend. In scenario 1 case 2 pollutant emission results, PM has the lowest emissions. The fastest routes have high $\mathrm{CO}$ emissions but eco routes show significant emission saving potential in VOC. This case also implies that eco routes have emission saving potential with respect to its alternative (Table 8).

Figure 16 shows that the three routes display the same trend in scenario 1 case 3 pollutant emission results. PM has the lowest emissions with respect to the other three pollutants. The fastest routes are a factor for high emissions. They have high CO emission. But eco routes show significant emission saving potential in VOC with respect to others (Table 9).
All results indicated the consideration of gradient variability when calculating the fuel consumption and Emission estimations from vehicles.

Therefore, eco routes in all tested scenarios are more environmentally friendly which implies eco routes have emission saving potential with respect to their alternative.

\section{Discussion}

The calculated results showed Fuel and emission Reduction in all tested scenarios. This study used MEET emissions factors because they reflect the characteristics of the Addis Ababa diesel fleet.

In this study, the applied model, which was previously presented took lessons and add values from the work of other authors' in several ways. This work encompasses 


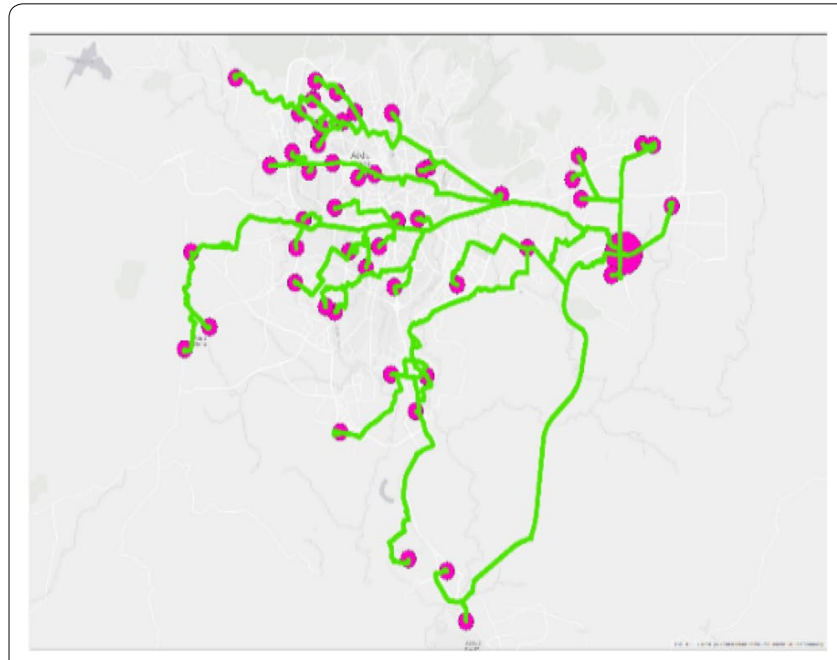

\section{Scenario 2 Case 3 Route Results}

\section{Legend}

- Destination Market

\section{Origin}
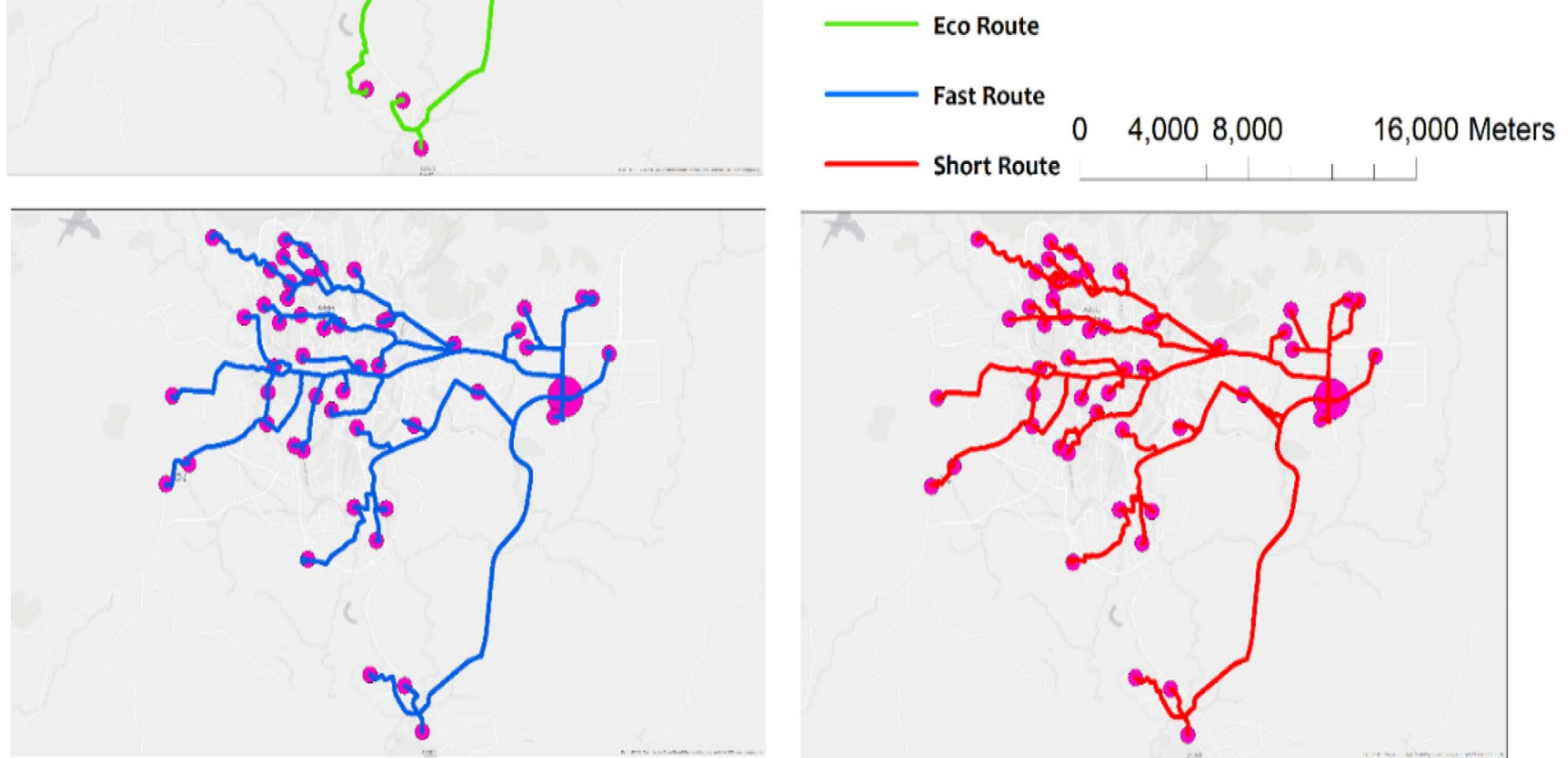

Fig. 10 Scenario 2 Case 3 routes

four steps: (1) Establishment Of 3D-RN (2) fuel consumption and pollutant emission estimation by using emission estimation model; (3) road network data set development and (4) optimization for different scenarios. Other attribute calculations are done by utilizing visual basic script options for different types of distribution vehicles. This is to minimize fuel consumption, distance, and time. Finally, the results were compared.

Zsigraiova et al. (2013) introduced a contrary methodology to estimate and reduce cost and emission. In this study Vehicle speed and weight are considered as influencing factors. However, optimization was not done for fuel consumption. The authors compared the emission levels in terms of distance and time only. The gradient effects on fuel consumption were also not considered. Around the same time, Pan et al. (2013) proposed that logistical mutualization at the strategic level be assessed from an environmental point of view. The study was able to predict the effect on reducing $\mathrm{CO}_{2}$ emissions by the integration of supply chains. In addition, road, and rail transports were considered in this paper. The findings of this study show that $\mathrm{CO}_{2}$ emission are reduced by the logistic mutualization approach. Whereas the effect of road gradient or inclination was also neglected.

If a digitized Road network and Digital elevation model are available, the proposed 3D eco route model works better for other study areas rather than Addis Ababa city. However, ultimate results of fuel and emission rates depend on the areas' gradient nature. This study estimates and reduces fuel consumption and emissions in the tested scenario areas in the Addis Ababa road network, which have a gradient range of around -8 to $8 \%$. In addition, the model was extended by adding different vehicle weight ranges. This was 


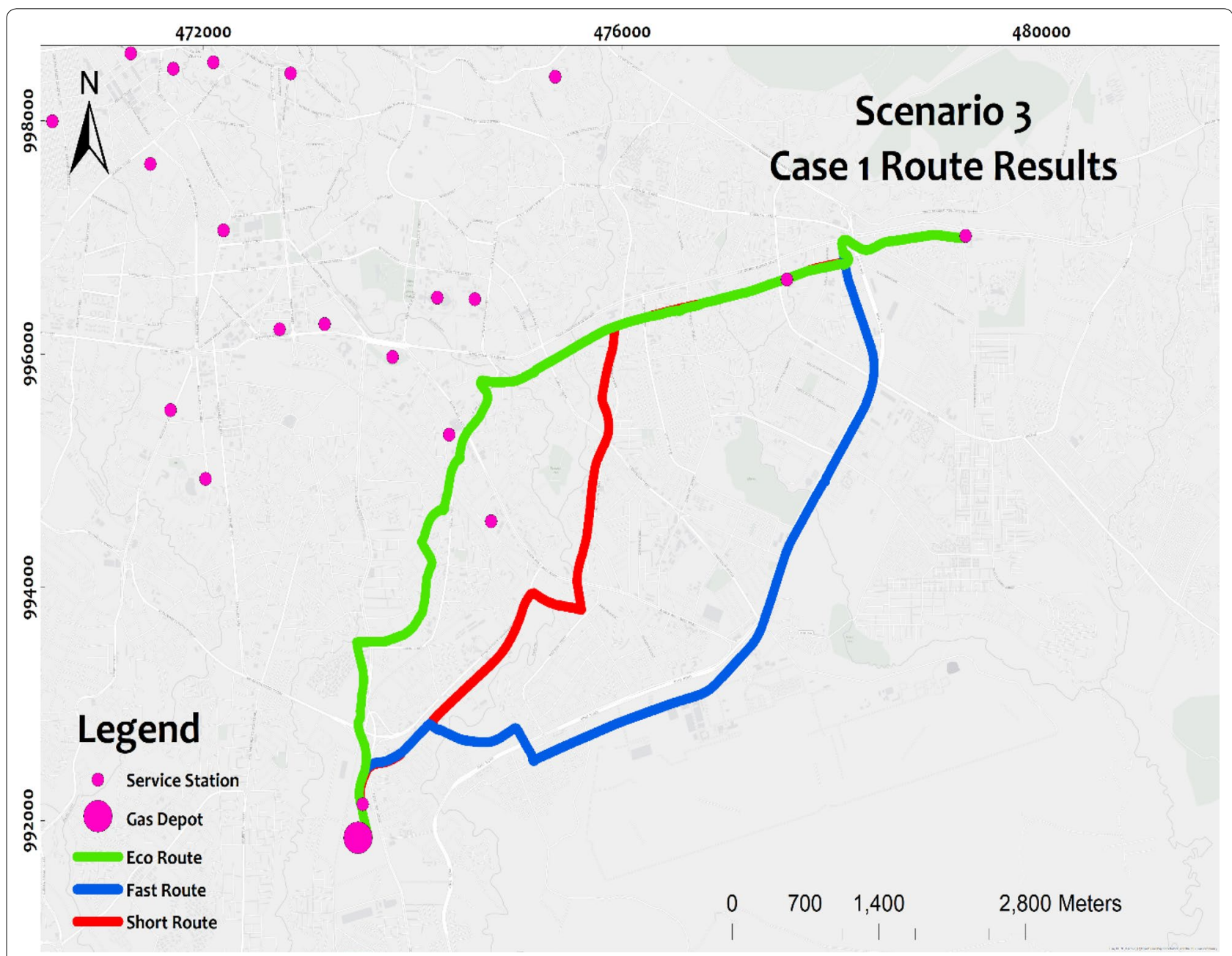

Fig. 11 Scenario 3 Case 1 routes

used to identify which range of vehicles significantly increases fuel consumption and pollutant emissions. Also, some restrictions, such as vehicle turning restrictions, were given to road networks, to use the street based on its functional importance in the street hierarchy. In addition, Elevation was considered to account for overpasses, underpasses and normal street networks to smoothly drive along delivery street. The company's distribution schedules were also studied. Accordingly, fuel consumption and emission rates are higher in the heavy-duty vehicle range of (16-32 tons) compared to heavy-duty vehicles ( $<16$ tons). This is because the data collected on the road network gradient around the gas depot and service stations shows an average gradient of around $4 \%$.

The applied 3D-eco routing-model offers a methodology which extends the abilities of prior works using
GIS, by incorporating different variables in one. The 3D eco Route models have the ability of estimating $\mathrm{FC}, \mathrm{CO}_{2}$ emission and air pollutants emission estimates for roadsegment by considering the Variables [Gradient, Speed, Vehicle Weight (3.5-32 tons)] using MEET Model in GIS environment. Therefore, the model does not depend on commercial solutions. Moreover, it optimizes the costs of private limited and governmental transport companies who want to reduce their environmental impact.

The numerical results confirm the importance of taking into account the terrain characteristics. From the analysis result, Eco-Routes were identified as having FC and $\mathrm{CO}_{2}$ saving potential of 8.39 to $39.81 \%$ to their alternatives. Consideration both elevation and route optimization through reduction of fuel consumption and emission are important factors for the management of distribution vehicles. These findings imply eco routes are better 


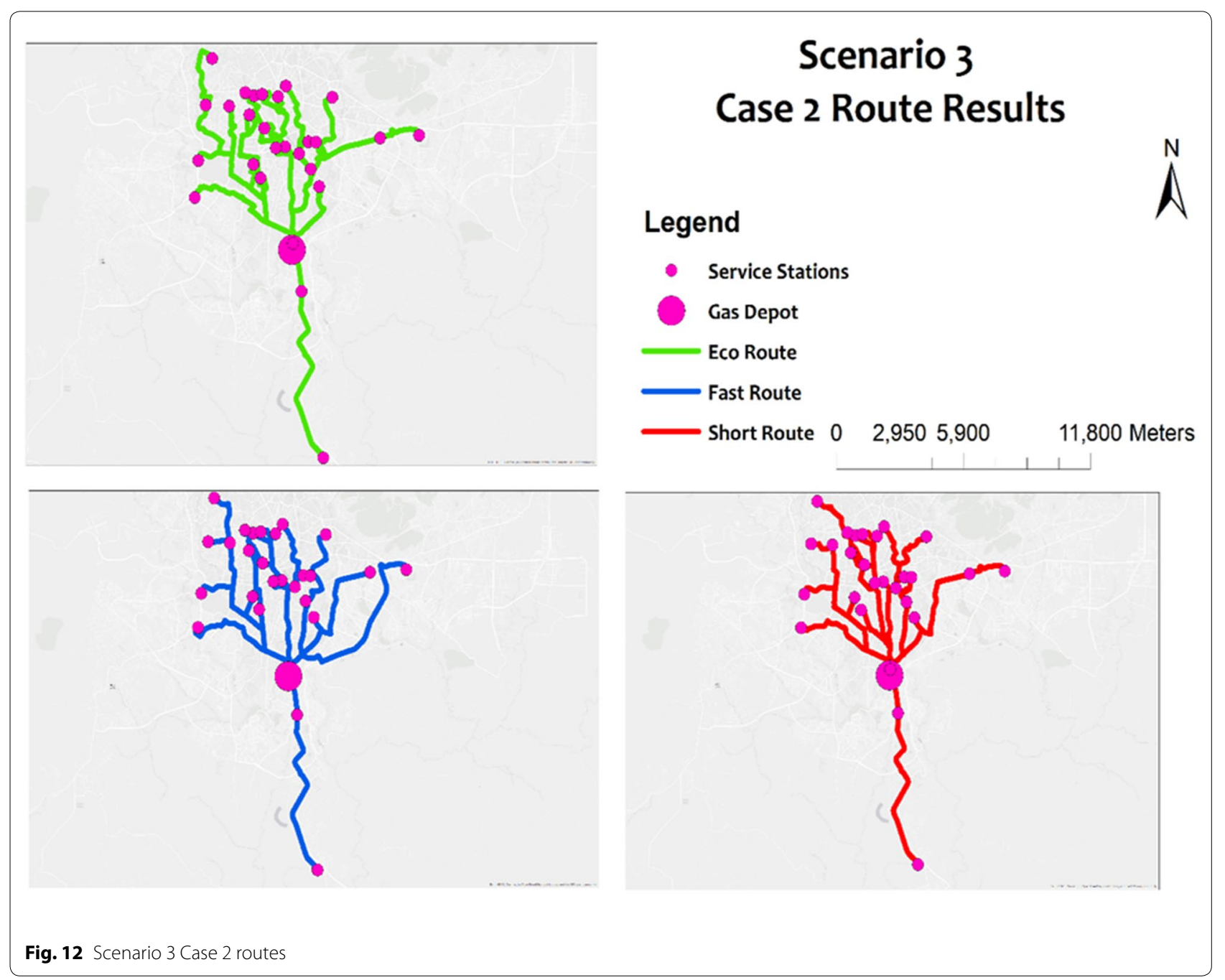

solutions for future sustainable road transport and also for the environment.

\section{Conclusion}

This study decisively addresses climate change and can bring significant benefits to Addis Ababa City. It can also help to avoid the runaway costs of climate change by the application of the model. The study model was applied in three scenarios each scenario contains three case studies. This study confirmed the method used was capable of reducing environmental footprint of vehicles in Addis Ababa City.

Emission saving was achieved when the optimizer was changed to the lowest 3D fuel consumption from the 3D distance and 3D Time. In the tested scenarios, substantial differences were detected among the shortest, fastest and eco routes under the same criteria. In the tested scenarios, Eco routes showed Fuel and $\mathrm{CO}_{2}$ emission reduction potential observed up to $39.82 \%$ from its alternatives.

Eco routes were found to be the most effective way to reduce fuel consumption, $\mathrm{CO}_{2}$ emissions and also air 


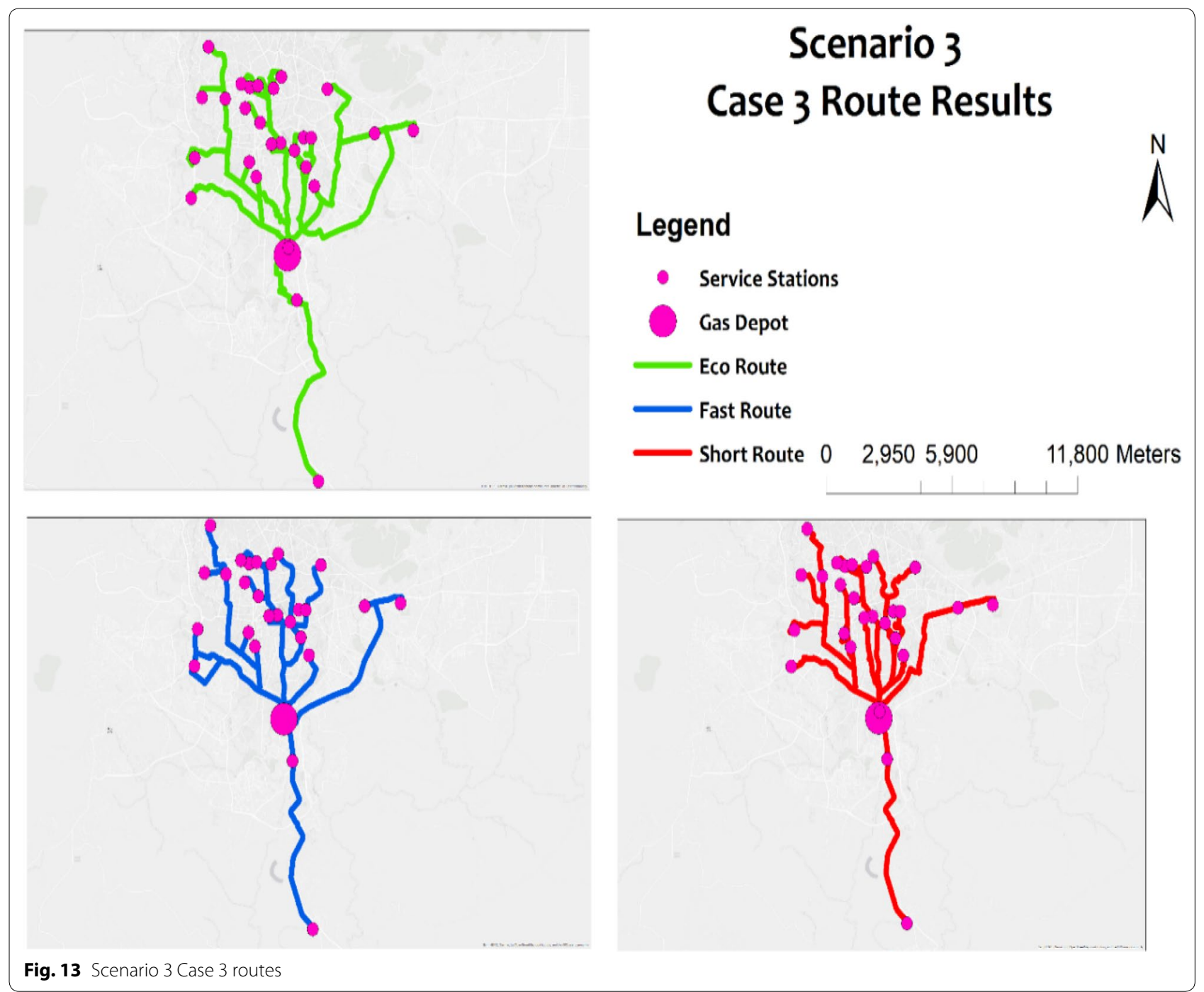

pollutants emission. Such potentials of eco routes make them an ecological solution for a future sustainable environment in Addis Ababa City. This is supported by the $3 \mathrm{D}$ eco route model.
This study provided baseline information on carbon emissions in Addis Ababa City and explored the implications of transportation activities with respect to Emissions in a new light. The current study suggested 


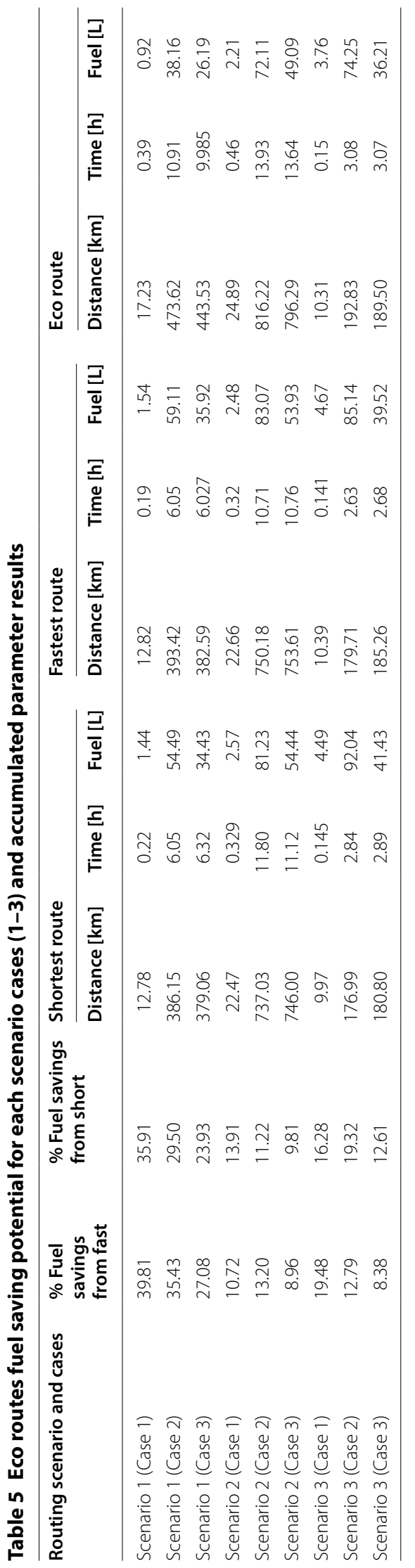


Table 6 Eco routes $\mathrm{CO}_{2}$ saving potential for each scenario cases (1-3) from its alternative routes parameter results

\begin{tabular}{|c|c|c|c|c|c|c|c|c|c|}
\hline \multirow[t]{2}{*}{ Routing scenario } & \multirow{2}{*}{$\begin{array}{l}\text { Vehicle weight } \\
\text { range and cases }\end{array}$} & \multirow{2}{*}{$\begin{array}{l}\% \mathrm{CO}_{2} \text { emission } \\
\text { savings from fast }\end{array}$} & \multirow{2}{*}{$\begin{array}{l}\% \mathrm{CO}_{2} \text { emission } \\
\text { savings } \\
\text { from short }\end{array}$} & \multicolumn{2}{|c|}{ Shortest route } & \multicolumn{2}{|c|}{ Fastest route } & \multicolumn{2}{|l|}{ Eco route } \\
\hline & & & & $\mathrm{CO}_{2}[\mathrm{~kg}]$ & Cost [\$] & $\mathrm{CO}_{2}[\mathrm{~kg}]$ & Cost [\$] & $\mathrm{CO}_{2}[\mathrm{~kg}]$ & Cost [\$] \\
\hline \multirow[t]{3}{*}{ Scenario 1} & $3.5-7.5$ ton $(\mathrm{C} 1)$ & 39.78 & 35.88 & 743.962 & 0.92 & 792.16 & 0.98 & 477.02 & 0.59 \\
\hline & $3.5-7.5$ ton $(C 2)$ & 35.43 & 29.96 & $27,991.40$ & 34.87 & $30,364.87$ & 37.83 & $19,604.46$ & 24.42 \\
\hline & $3.5-7.5$ ton $(\mathrm{C} 3)$ & 27.08 & 23.93 & $17,689.08$ & 22.04 & $18,451.50$ & 22.99 & $13,454.62$ & 16.76 \\
\hline \multirow[t]{3}{*}{ Scenario 2} & 7.5-16 ton (C1) & 10.73 & 13.89 & 1321.69 & 1.64 & 1274.80 & 1.58 & 1138.00 & 1.41 \\
\hline & $7.5-16$ ton (C2) & 13.20 & 11.22 & $41,722.13$ & 51.98 & $42,671.03$ & 53.16 & $37,037.95$ & 46.15 \\
\hline & 7.5-16 ton (C3) & 8.96 & 9.81 & $27,962.18$ & 34.84 & $27,700.64$ & 34.51 & $25,216.77$ & 31.42 \\
\hline \multirow[t]{3}{*}{ Scenario 3} & $16-32$ ton $(\mathrm{C} 1)$ & 19.48 & 16.27 & 2309.35 & 2.87 & 2401.62 & 2.99 & 1933.61 & 2.40 \\
\hline & $16-32$ ton (C2) & 12.79 & 19.32 & $47,276.36$ & 58.90 & $43,735.45$ & 54.49 & $38,139.80$ & 47.25 \\
\hline & $16-32$ ton (C3) & 8.39 & 12.61 & $21,284.08$ & 26.52 & $20,303.11$ & 25.29 & $18,599.39$ & 23.17 \\
\hline
\end{tabular}

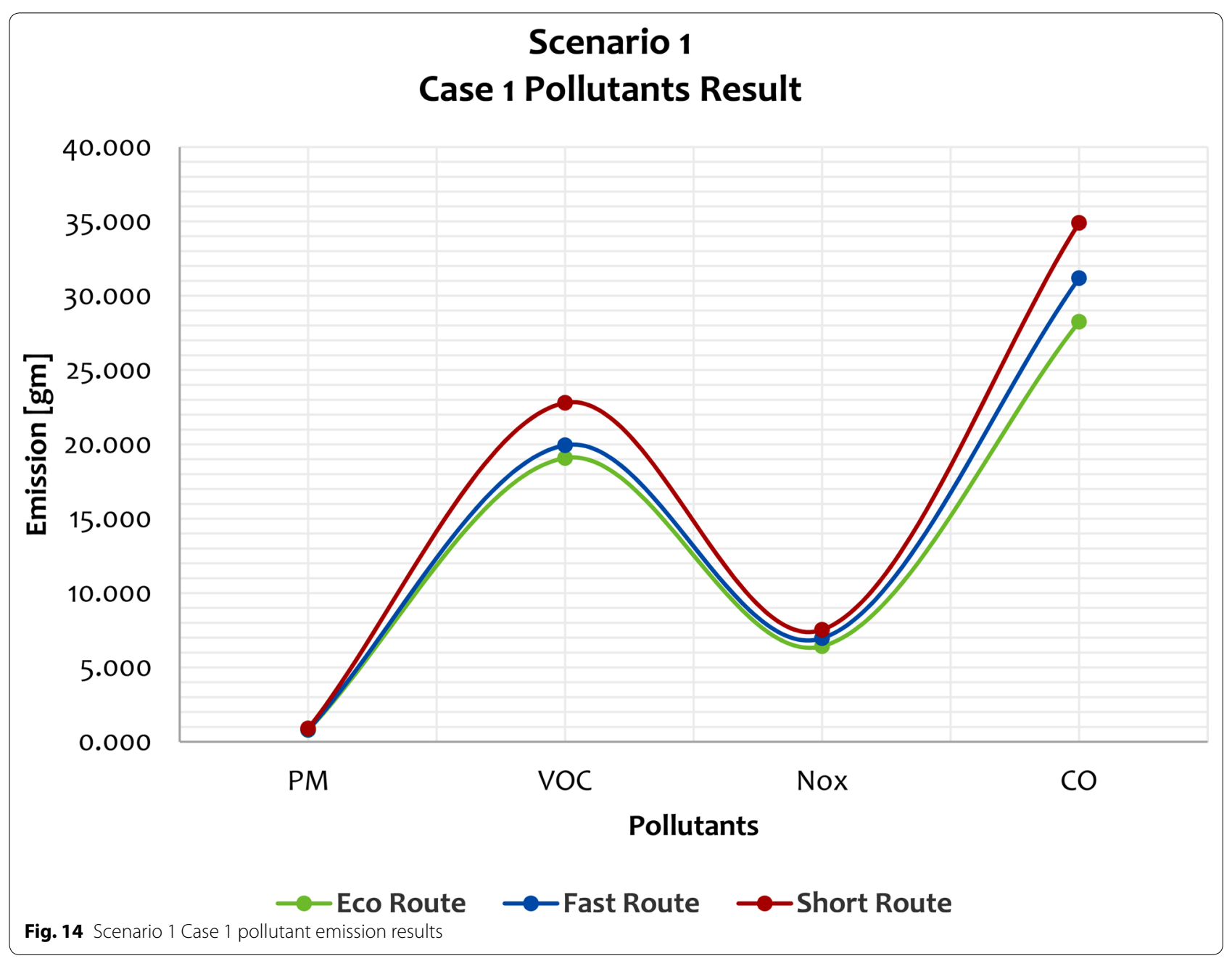


Table 7 Scenario 1 Case 1 eco route emission saving potential for each air pollutant accumulated results

Eco routes pollutants emission saving potential in \%

\begin{tabular}{lrrrl}
\hline & PM & VOC & NOx & CO \\
\hline From fastest route & 2.306 & 4.327 & 7.717 & 9.4023 \\
From shortest route & 12.193 & 16.295 & 14.685 & 19.050 \\
\hline
\end{tabular}

Table 8 Scenario 1 Case 2 eco route emission saving potential for each air pollutant accumulated results

Eco routes pollutants emission saving potential in \%

\begin{tabular}{lrrrr}
\hline & PM & VOC & NOx & \multicolumn{1}{c}{ CO } \\
\hline From fastest route & 0.304 & 22.845 & 14.086 & 16.863 \\
From shortest route & 1.177 & 8.423 & 3.833 & 6.580 \\
\hline
\end{tabular}

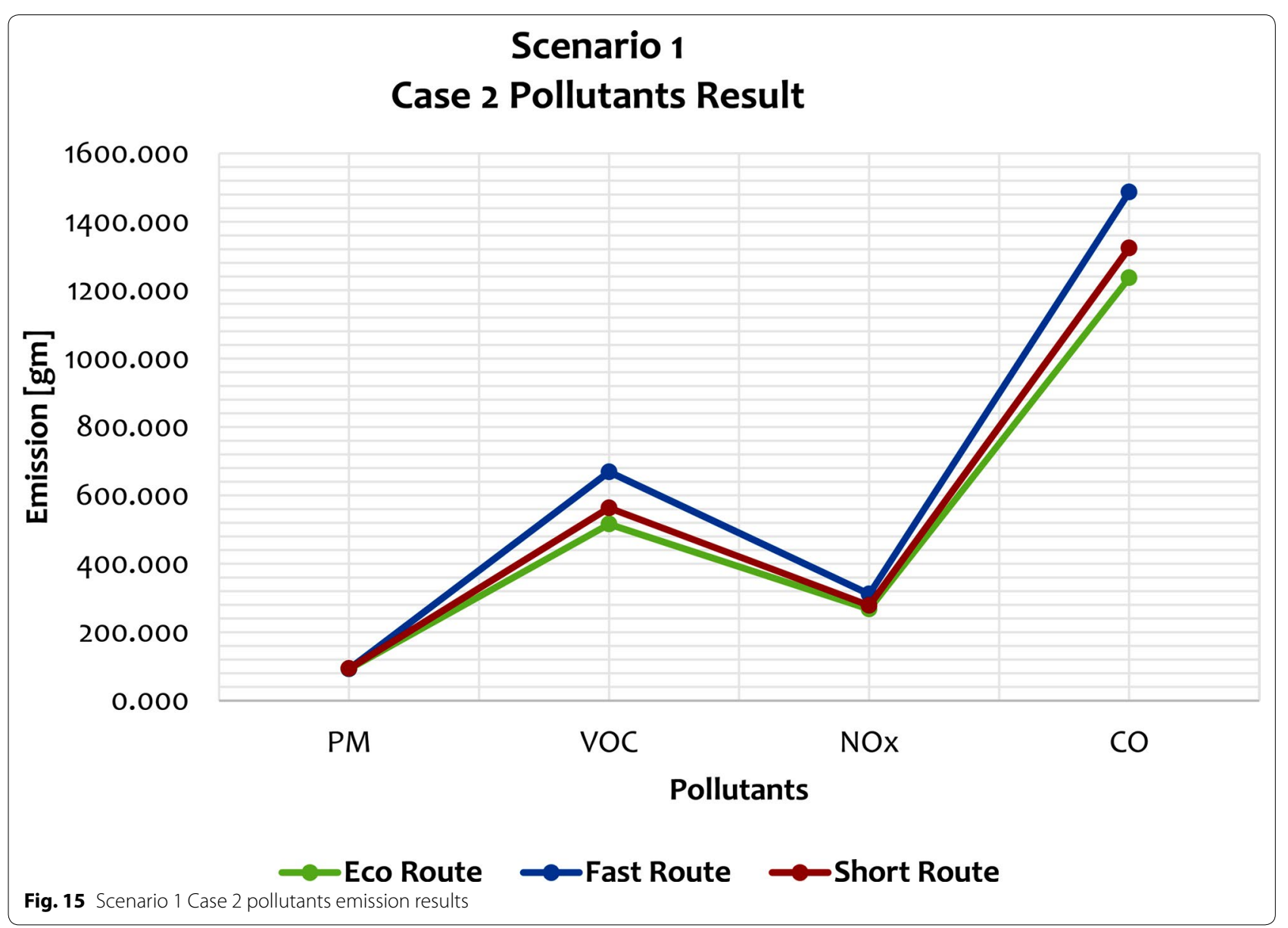




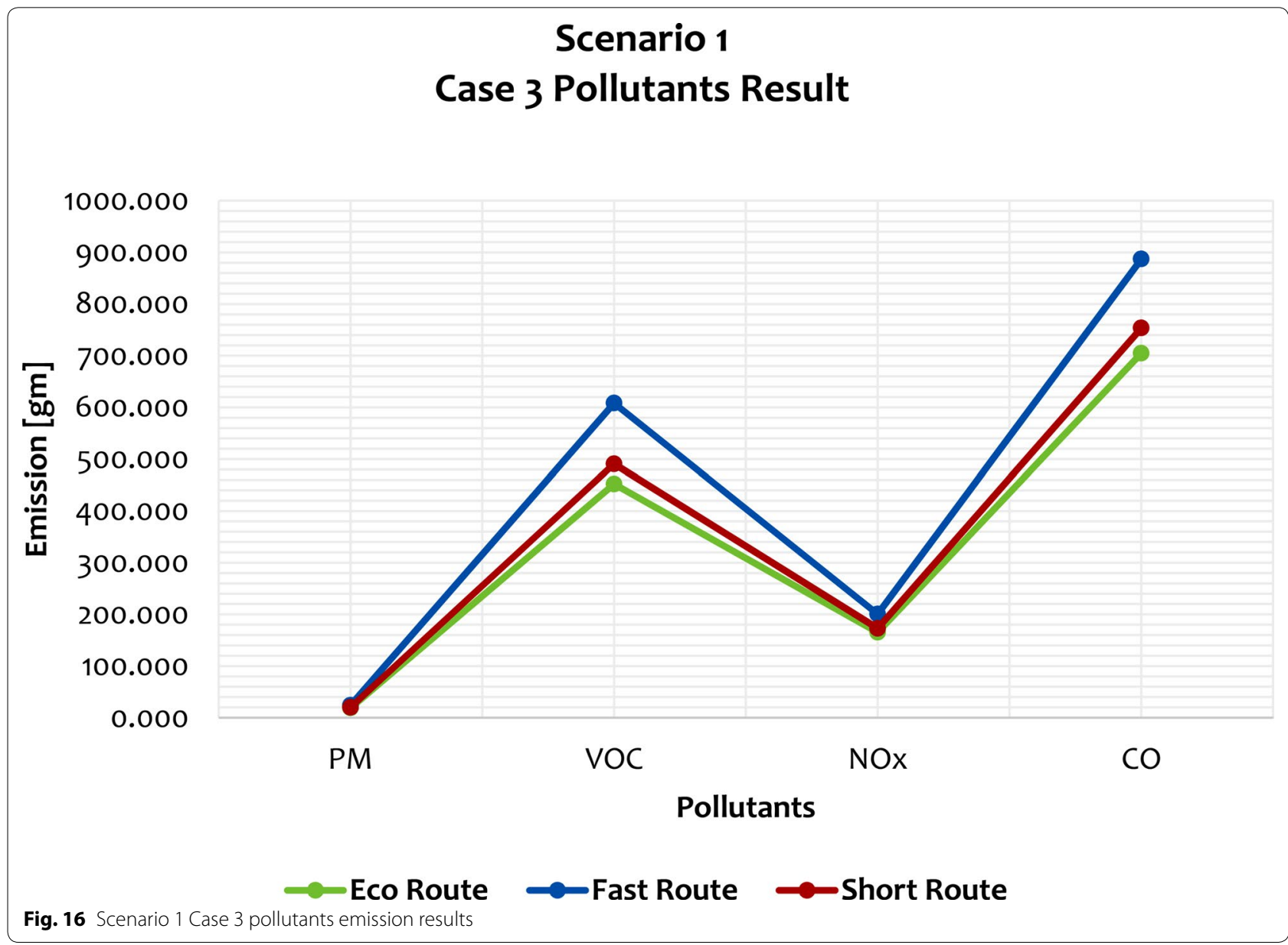

Table 9 Scenario 1 Case 3 eco route emission saving potential for each air pollutant accumulated results

Eco routes pollutants emission saving potential in \%

\begin{tabular}{lrrrr}
\hline & PM & VOC & NOx & \multicolumn{1}{c}{ CO } \\
\hline From fastest route & 22.070 & 25.650 & 17.597 & 20.538 \\
From shortest route & 5.776 & 7.889 & 4.410 & 6.474 \\
\hline
\end{tabular}

ways that the transportation industry can adjust its transport investment activities to reduce carbon emissions by utilizing Eco routes. It is very much expected that the proposed eco-route Model can contribute to the development of a low-carbon transportation system in Addis Ababa City.

\section{Abbreviations}

FC: Fuel consumption; GCF: Gradient correction factor; HDV: Heavy duty vehicle; Lcf: Load correction factor; Lp: Load factor; RG: Road gradient.

\section{Acknowledgements}

We would like to thank the anonymous reviewers and the editor for their genuine comments and corrections which helps the paper to be in its present form.

\section{Authors' contributions}

SWB has conceived of the study and made contributions in design, data collection, analysis, interpretation of results and draft the manuscript. DA has participated in the sequence alignment and critical commenting of the manuscript. Both authors read and approved the manuscript.

\section{Funding}

No funding was received.

\section{Availability of data and materials}

The datasets used and/or analysed during the current study are available from the corresponding author on reasonable request.

Ethics approval and consent to participate Not Applicable.

\section{Consent for publication}

We have agreed to submit for Environmental Systems Research journal and approved the manuscript for submission.

\section{Competing interests}

The authors declare that they have no competing interests. 


\section{Author details}

${ }^{1}$ Geomatics and Geoinformatics Engineering Chair, School of Civil Engineering and Architecture, Dire Dawa University, P.O. Box:1362, Dire Dawa, Ethiopia.

${ }^{2}$ Geomatics Engineering Department, School of Civil Engineering and Architecture, Adama Science and Technology University, P.O. Box: 1888, Adama, Ethiopia.

Received: 9 March 2020 Accepted: 28 July 2020

Published online: 06 August 2020

\section{References}

Addis Ababa City Transport Authority 2019. http://www.aacta.gov.et/. Accessed 19 Oct 2019

Andersen O, Jensen CS, Torp K, Yang B (2013) EcoTour: reducing the environmental footprint of vehicles using eco-routes. Proc IEEE Int Conf Mobile Data Manag 1:338-340

Arora A, Pandey MK 2011. Transportation network model and network analysis of road networks Abstract: About the Author:" 12th Esri India User Conference 2011: 1-9. http://www.esri.in/ /media/esri-india/files/pdfs/events/ uc2011/papers/Infra_UCP002.pdf

Bartlett R (2015) Road gradient - (1) definition and vehicle performance|Comparative Geometrics. https://comparativegeometric swordpress.com/2015/12/10/road-gradient-1-definition-and-vehicleperformance/ Accessed 2 Feb 2018

Baumert K, Herzog T, Jonathan P (2005) \|N Navigating the numbers greenhouse gas data and international climate policy\|l. World Resources Institute, United States of America

Cervero R, Golub A (2007) Informal transport: a global perspectivell. Transp Policy 14(6):445-457

Coloma JF, García M, Wang Y, Monzón A (2017) Green Eco-Driving Effects in Non-Congested Cities. Sustainability 10(1):1-16

Demir Emrah, Bektaş Tolga, Laporte Gilbert (2014) A review of recent research on green road freight transportation. Eur J Oper Res 237(3):775-793

EEA. 1999. "Emission Inventory Guidebook: Road Transport."

Huang, Xianan, and Huei Peng. 2018. "Eco-Routing Based on a Data Driven Fuel Consumption Model." (i). http://arxiv.org/abs/1801.08602

Jovičić NM et al (2010) Route Optimization to Increase Energy Efficiency and Reduce Fuel Consumption of Communal Vehicles. Thermal Science 14(1):67-78

Keenan PB (1998) Spatial Decision Support Systems for Vehicle Routing. Decis Support Syst 22(1):65-71

Kousoulidou M, Ntziachristos L, Gkeivanidis S, Samaras Z, Franco V, Dilara P (2010) Validation of the COPERT road emission inventory model with realuse data. In Emissions Inventories_-Informing Emerging Issues (p. 40). https://www3.epa.gov/ttnchie1/conference/ei19/session6/dilara.pdf

LAT/EEA (2007) COPERT 4-Computer programme to calculate emissions from road transport. Copenhagen, Denmark

Li C et al (2014) Optimization of MSW collection routing system to reduce fuel consumption and pollutant emissions key words. Nat Environ Pollut Technol 13(1):177-184
Madan B (2012) Climate change and transport: assessment of frieght modal shift and emission through dry port development, Phd Dissertation. Transport Study Unit, Tokyo Institute of Technology, Tokyo

Minett CF, Salomons AM, Daamen W, Van Arem B (2011) Eco-routing: comparing the fuel consumption of different routes between an origin and destination using field test speed profiles and synthetic speed profiles. In: 2011 IEEE forum on integrated and sustainable transportation systems. IEEE, Vienna, Austria. https://doi.org/10.1109/FISTS.2011.5973621

Pan Shenle, Ballot Eric, Fontane Frédéric (2013) The reduction of greenhouse gas emissions from freight transport by pooling supply chains. Int J Prod Econ 143(1):86-94

Schröder M, Cabral P (2019) Eco-friendly 3D-routing: a GIS Based 3D-routingmodel to estimate and reduce $\mathrm{CO}_{2}$-emissions of distribution transports. Comput Environ Urban Syst 73(2018):40-55. https://doi.org/10.1016/j. compenvurbsys.2018.08.002

Scora G, Boriboonsomsin K, Barth M (2015) Research in transportation economics value of eco-friendly route choice for heavy-duty trucks. Res Transp Econ 52:3-14. https://doi.org/10.1016/j.retrec.2015.10.002

Tavares G, Zsigraiova Z, Semiao V, Carvalho MG (2009) Optimisation of MSW collection routes for minimum fuel consumption using 3D GIS modelling. Waste Manage 29(3):1176-1185. https://doi.org/10.1016/j.wasma n.2008.07.013

The Geography of Transport System (2006). https://www.transportgeography. org. Accessed 21 Oct 2019

Toro E, Hernando A, Zuluaga E, Granada-echeverri M (2016) Literature review on the vehicle routing problem in the green transportation context. Luna Azul 42:362-387. https://doi.org/10.17151/luaz.2016.42.21

Zsigraiova Z, Semiao V, Beijoco F (2013) Operation costs and pollutant emissions reduction by definition of new collection scheduling and optimization of MSW collection routes using GIS. The Case Study of Barreiro, Portugal. Waste Manage 33:793-806

\section{Publisher's Note}

Springer Nature remains neutral with regard to jurisdictional claims in published maps and institutional affiliations.

\section{Submit your manuscript to a SpringerOpen ${ }^{\odot}$ journal and benefit from:}

- Convenient online submission

- Rigorous peer review

- Open access: articles freely available online

- High visibility within the field

Retaining the copyright to your article

Submit your next manuscript at springeropen.com 